\title{
Surprisingly high economic costs of biological invasions in protected areas
}

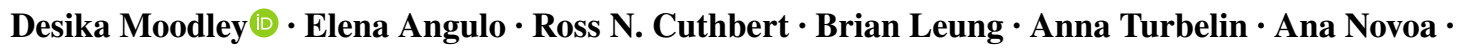 \\ Melina Kourantidou • Gustavo Heringer · Phillip J. Haubrock • David Renault • Marine Robuchon • \\ Jean Fantle-Lepczyk · Franck Courchamp · Christophe Diagne
}

Received: 1 March 2021 / Accepted: 1 January 2022 / Published online: 4 February 2022

(C) The Author(s) 2022

\begin{abstract}
Biological invasions are one of the main threats to biodiversity within protected areas (PAs) worldwide. Meanwhile, the resilience of PAs to invasions remains largely unknown. Consequently, providing a better understanding of how they are impacted by invasions is critical for informing policy responses and optimally allocating resources to prevention and control strategies. Here we use the InvaCost database to address this gap from three
\end{abstract}

Supplementary Information The online version contains supplementary material available at https://doi. org/10.1007/s10530-022-02732-7.

D. Moodley $(\bowtie) \cdot$ A. Novoa

Institute of Botany, Department of Invasion Ecology,

Czech Academy of Sciences, CZ-252 43, Průhonice,

Czech Republic

e-mail: desikamoodley29@gmail.com

E. Angulo - A. Turbelin · F. Courchamp - C. Diagne Université Paris-Saclay, CNRS, AgroParisTech, Ecologie

Systématique Evolution, 91405 Orsay, France

R. N. Cuthbert

GEOMAR, Helmholtz-Zentrum Für Ozeanforschung Kiel, 24105 Kiel, Germany

R. N. Cuthbert

School of Biological Sciences, Queen's University Belfast, Belfast BT9 5DL, Northern Ireland, UK

B. Leung

Department of Biology, McGill University, Montréal, QC, Canada perspectives: (i) characterizing the total reported costs of invasive alien species (IAS) in PAs; (ii) comparing mean observed costs of IAS in PAs and non-PAs; and (iii) evaluating factors affecting mean observed costs of IAS in PAs. Our results first show that, overall, the reported economic costs of IAS in PAs amounted to US\$ 22.24 billion between 1975 and 2020, of which US\$ 930.61 million were observed costs (already incurred) and US\$21.31 billion were potential costs (extrapolated or predicted). Expectedly, most of the observed costs were reported for management (73\%) but damages were still much higher than expected for PAs (24\%); in addition, the vast majority of man-

\author{
M. Kourantidou \\ Institute of Marine Biological Resources and Inland \\ Waters, Hellenic Center for Marine Research, \\ 16452 Athens, Greece \\ M. Kourantidou \\ Department of Sociology, Environmental and Business \\ Economics, University of Southern Denmark, Degnevej \\ 14, 6705 Esbjerg Ø, Denmark \\ G. Heringer \\ Programa de Pós-Graduação em Ecologia Aplicada, \\ Departamento de Ecologia e Conservação, Instituto de \\ Ciências Naturais, Universidade Federal de Lavras - \\ UFLA, Lavras, Minas Gerais 37200-900, Brazil
}

agement costs were reported for reactive, post-invasion actions ( $84 \%$ of management costs, focused on eradication and control). Second, differences between 
costs in PAs and non-PAs varied among continents and environments. We found significantly higher IAS costs in terrestrial PA environments compared to nonPAs, while regionally, Europe incurred higher costs in PAs and Africa and Temperate Asia incurred higher costs in non-PAs. Third, characterization of drivers of IAS costs within PAs showed an effect of environments (higher costs in terrestrial environments), continents (higher in Africa and South America), taxa (higher in invertebrates and vertebrates than plants) and Human Development Index (higher in more developed countries). Globally, our findings indicate that, counterintuitively, PAs are subject to very high costs from biological invasions. This highlights the need for more resources to be invested in the management of IAS to achieve the role of PAs in ensuring the long term conservation of nature. Accordingly, more spatially-balanced and integrative studies involving both scientists and stakeholders are required.

Keywords Invasive alien species - InvaCost · Biodiversity conservation · Monetary impacts . Management actions · Protection status

\section{Introduction}

Biological invasions represent a global environmental problem and management challenge (Pyšek et al. 2020; Ricciardi et al. 2021). The plethora of environmental impacts posed by invasive alien species (IAS) range from declines in biodiversity (Ellstrand and Schierenbeck 2000; Vilà et al. 2000; Hejda et al. 2009; Butchart et al. 2010) to disruption of ecological

\footnotetext{
P. J. Haubrock

Faculty of Fisheries and Protection of Waters, South Bohemian Research Center of Aquaculture and Biodiversity of Hydrocenoses, University of South Bohemia in České Budějovice, Zátiší 728/II, 38925 Vodňany, Czech Republic

P. J. Haubrock

Department of River Ecology and Conservation, Senckenberg Research Institute and Natural History Museum Frankfurt, Gelnhausen, Germany

D. Renault

Univ Rennes, CNRS, ECOBIO [(Ecosystèmes, biodiversité, évolution)] - UMR 6553, 35000 Rennes, France
}

processes and provisioning of ecosystem services (Vitousek 1990; Charles and Dukes 2008; Pejchar and Mooney 2009; Ehrenfeld 2010). IAS also negatively impact human health and well-being (Conn 2014; Hulme 2014; Mazza and Tricarico 2018; Schaffner et al. 2020), and cause losses to multiple sectors of the economy (Pimentel et al. 2005; Martins et al. 2006; Kettunen et al. 2009; Paini et al. 2016; Diagne et al. 2021). Alarmingly, with no signs of abatement in the numbers of established alien species in recent decades, their associated environmental, social and economic impacts will likely continue to substantially increase in the foreseeable future (Seebens et al. 2017, 2020; Bailey et al. 2020). As a result, there is an urgent need for establishing effective management responses. One way of achieving this is by effectively managing IAS in areas that protect a broad range of species and habitats, such as protected areas (PAs) - a pillar for global biodiversity conservation efforts.

With $15.7 \%$ of the global land surface and $7.9 \%$ of the ocean (www.protectedplanet.net/) currently covered in the network of PAs, the designation of PAs has been a critical means of mitigating biodiversity threats worldwide. In addition, the European Union plans to protect $30 \%$ of its land and sea territory by 2030 (https://eur-lex.europa.eu/legal-content/EN/ TXT/?uri=CELEX:52020DC0380). PAs worldwide comprise a large range of designations with different management regimes, ranging from highly to minimally protected sites. When appropriately designed and successfully managed, PAs can be effective in conserving native biodiversity (including species of conservation concern), maintaining ecosystem function and keeping ecosystem services intact (Chape

\author{
D. Renault \\ Institut Universitaire de France, 1 Rue Descartes, \\ 75231 Paris cedex 05, France \\ M. Robuchon \\ Joint Research Centre (JRC) of the European Commission, \\ Directorate for Sustainable Resources, 21027 Ispra, VA, \\ Italy \\ J. Fantle-Lepczyk \\ School of Forestry \& Wildlife Sciences, Auburn \\ University, Auburn, AL 36849, USA
}


et al. 2005; Foxcroft et al. 2011; Geldmann et al. 2013; Daněk et al. 2017; Ziller et al. 2020). Effectiveness of PAs for biodiversity conservation can be measured in many different ways, depending on the conservation goals in place. For example, PA network design can be assessed to determine the diversity of species and habitats, and/or inclusion of the highest priority conservation areas to meet global biodiversity conservation goals (Rodrigues and Gaston 2001; Rodrigues et al. 2004; Le Saout et al. 2013; Heringer et al. 2020). However, regardless of their official designation, PAs tend to be more vulnerable and challenged by IAS than unprotected landscapes, since they often host a larger proportion of native, endemic and threatened species which are less adapted to anthropogenic disturbances (Foxcroft et al. 2013; Heringer et al. 2020).

Understanding the economic costs of IAS is critical to ensure adequate funding for conservation efforts and to design appropriate management actions that will help mitigate impacts and safeguard biodiversity (Dana et al. 2014; Diagne et al. 2020a). However, a detailed understanding of the costs incurred by IAS is still lacking for PAs. A preliminary analysis of the number of post-1970 English-language publications available in the Web of Science on costs of biological invasions (Supplementary Material 1), showed that despite the numerous IAS publications $(\mathrm{n}=58,729)$, studies involving PAs have received relatively little attention (12.6\%), and only a few of these evaluate the economic costs in PAs (1.6\%). Many IAS studies in PAs have attempted to decipher the drivers of invasions (Gaertner et al. 2014; Gantchoff et al. 2018; Iacarella et al. 2020; Liu et al. 2020; Moodley et al. 2020), thereby improving our understanding of the role of designation type (i.e. nationally designated PAs, such as national parks, have fewer IAS), designation year (i.e. younger PAs have more IAS), PA size (i.e. larger PAs have more IAS) and/or human activities (i.e. IAS increases with accessibility and higher human footprint index) in driving the success and impacts of IAS in PAs (Gallardo et al. 2017; Liu et al. 2020). Yet, despite progress in our knowledge of these ecological and environmental drivers of invasions in PAs, the incurred economic impacts from IAS, and ability to mitigate them, remain unexplored. Moreover, while there is evidence that geographic bias (towards North America and the Pacific Islands) and taxonomic bias (towards plants and insects) largely drive our understanding of IAS success and impact (Pysek et al. 2008; Hulme et al. 2014), thus far, there has been little effort made on exploring the global patterns of IAS in PAs.

To fill the knowledge gaps on the cost of biological invasions in PAs worldwide, we structured our study around three broad aims, each employing a distinct subset of the InvaCost database (see Materials and Methods and Fig. 1). Specifically, we sought to: (i) characterize the overall costs of IAS within PAs, based on an all-inclusive PA dataset: we expected higher costs dedicated to management (which prevents the introduction or mitigates the impacts of IAS) than to damage; (ii) investigate whether observed IAS costs (i.e. excluding potential costs, see below) differ between PAs and non-PAs, using carefully matched criteria and after accounting for other factors (i.e. environment, taxonomy, geography, type of costs and economic sectors): we expected lower costs in PAs, which should be better protected from invasion and contain less economic assets; and (iii) further examine which economic and PA characteristics (e.g. year of designation, PA size) drive differences in IAS-related costs, using a subset of PAs with observed cost data: we expected that costs within PAs are driven by both protection and economic characteristics.

\section{Materials and methods}

\section{Original data}

We used information from the InvaCost database (version 4.0 containing 13,123 entries; openly available at https://doi.org/10.6084/m9.figshare.12668 570), the most recent, comprehensive database on globally reported economic costs of IAS in English and 15 other languages (Diagne et al. 2020b; Angulo et al. 2021). Each database entry contains a cost value associated to a unique combination of cost descriptors, including: (i) bibliography of the documents reporting the costs; (ii) details on the impacted area (e.g. location, spatial scale, environment, and whether the location corresponded to a protected area); (iii) taxonomy of the IAS causing the cost, (iv) temporal extent over which the cost occurred, or was predicted to occur; (v) type of cost: whether the cost is a management action 


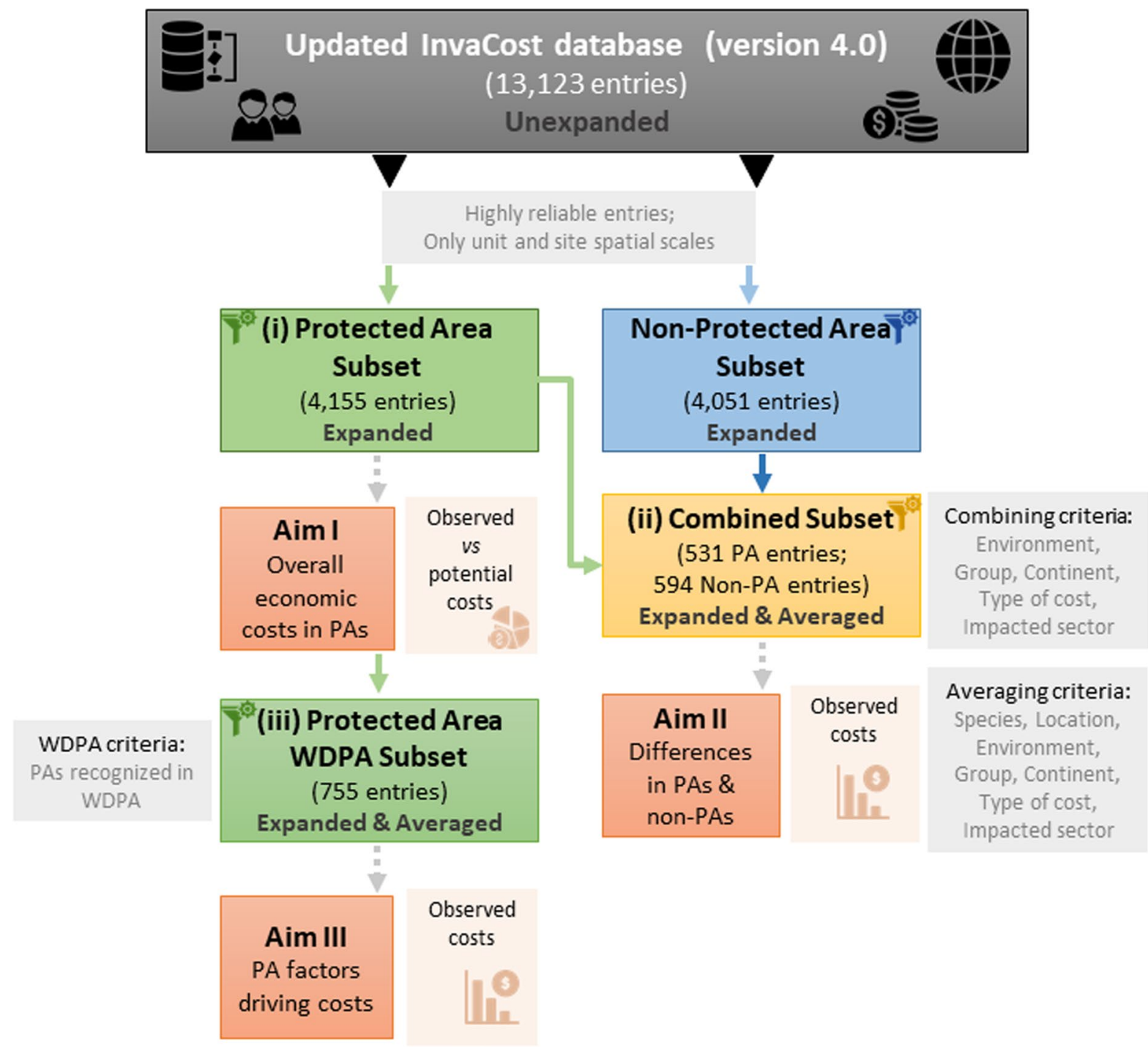

Fig. 1 Workflow chart detailing the filtering process and cost entry eligibility, carefully designed to address the three study aims. Opaque, gray boxes indicate the main criteria used to filter each subset while opaque, orange boxes indicate whether

or an economic damage; (vi) implementation of the cost: whether the cost was observed (actually incurred) or potential (extrapolated or predicted to occur); (vii) impacted sector (which activity, market or societal sector was related to the cost); and (viii) reliability of the source document providing the cost estimate (whether the cost source was peerreviewed, official and/or reproducible, or not). To the subset contains observed (i.e. cost incurred by an IAS) and/ or potential costs (i.e. extrapolation cost for an IAS beyond its current distribution and/or predicted in the future within or beyond its current invasive range)

allow for comparable cost values, all cost estimates were standardized and converted to 2017 US\$ (Diagne et al. 2020b). We re-classified some of the original columns of the InvaCost database to ensure that our study is comparable with other PA studies (Supplementary Material 2) and then filtered and extracted the data into different subsets as described below (all subsets are available in Supplementary Material 3). 
Data processing

\section{Data preparation}

To obtain robust subsets from the original database, we only included highly reliable and appropriatelyspatially scaled cost entries (Fig. 1). Specifically, we first filtered the Reliability cost descriptor column to only select those costs characterised as having "high" reliability. This distinction of the cost entries into having "high" or "low" reliability, indicates if the approach used for cost estimation in the original source is reported, reproducible and traceable (see Diagne et al. 2020b for details on criteria used). Second, we filtered the Spatial scale cost descriptor column to exclude those estimated at "country" and "regional" scales. Rather, we only considered those at the "site" and "unit" scales, since these are the spatial scales in which PA costs occur. Subsequently, we used the information provided in the protectedArea column to identify the status of land protection for each cost entry: "yes", only pertaining to protected areas; "no", only pertaining to non-protected areas; or "NA", when there was no information about the status or when costs were attached to both protected and non-protected areas. We excluded entries that were identified as "NA".

We further refined the resulting dataset to specifically address the aims of this study. Thus, we applied consecutive filtering procedures which resulted in the creation of three subsets (Fig. 1): (i) PA cost entries only (hereafter referred to as the Protected Area Subset; see subset details below); (ii) costs for protected and non-protected areas together, to examine the effect of protected areas on cost, after controlling for other variables (hereafter referred to as the Combined Subset; see subset details below); and (iii) costs for PAs listed in the World Database on Protected Areas (WDPA; UNEP-WCMC and IUCN 2020), which allowed the addition of WDPA descriptor variables (hereafter referred to as the Protected Area WPDA Subset; see subset details below).

All cost estimates were annualized in the original database (see Cost estimate per year columns; Diagne et al. 2020b). Here, we expanded all subsets (Subsets i-iii in Fig. 1) to account for the duration (in years) of each cost estimate by using the expandYearlyCosts function of the 'invacost' package version 0.3-4 (Leroy et al. 2020). This function relies on information contained in the Probable starting year adjusted and Probable ending year adjusted columns to repeat each annualized cost as many times as years of cost occurrence. This resulted in comparable annual costs for all cost entries (i.e. expanded format) which are unbiased with respect to time. As an illustration, cost estimates spanning multiple years (e.g. $\$ 10$ million for the period 2006-2010) are divided according to their duration (e.g. \$2 million for each year between 2006 and 2010).

\section{Averaging annualized costs estimates}

For the Combined Subset and the Protected Area WDPA Subset (Subsets ii and iii in Fig. 1), we averaged the annual cost values across descriptors so that individual entries associated with a single species from the same location and environment, which incur the same type of costs and affect the same activity sectors, were averaged into one single cost entry (Fig. 1, Supplementary Material 2 and 3 for the interpretation of these descriptive fields and the subsets). This allowed us to control for pseudoreplication and also partition the effect of these factors when estimating the effect of PAs. All statistical analyses presented in the main text were performed on these expanded and averaged subsets.

\section{The protected area subset}

Filtered and expanded entries classified as PAs (i.e. "yes" in the protectedArea column) resulted in the Protected Area Subset with a total of 4155 cost entries, which was used to describe economic trends associated with IAS in PAs (Subset $i$ in Fig. 1). Regarding the temporal variation of the costs of IAS in PAs, we used the summarizeCosts function of the 'invacost' $\mathrm{R}$ package to quantify annual average costs at five-year intervals between 1975 and 2020 (Leroy et al. 2020). We considered both the magnitude of costs (in 2017 US\$), as well as the number of cost entries (expanded) over time. We also investigated the spatial distribution of PA associated costs by continents, explored the taxonomic groups responsible for costs in PAs, and categorised the type of costs and the economic sectors impacted by the cost. Moreover, we examined costs separately for observed costs (i.e. if the cost was actually incurred) and potential costs (i.e. if the cost was extrapolated or predicted to occur) 
using the Implementation column. It is expected that potential costs will be higher than observed costs, because observed costs are restricted to actual, often hardly-quantifiable impacts that are monetized in a limited time frame and in areas of established invasions. Conversely, potential costs are extrapolations or predictions of costs that will occur in the future or in the probable IAS range. However, potential costs should not be ignored, since they provide information concerning costs that are difficult to quantify or may occur under different scenarios. Thus, we report potential costs in PAs using this complete subset, but clearly distinguish them.

\section{The combined subset}

A total of 4,051 cost entries were identified in nonPAs (i.e. "no" in the protectedArea column) and constituted the Non-protected Area Subset (Fig. 1). The Combined Subset comprises the Non-protected Area Subset and the Protected Area Subset, and further filters cost entries of both subsets by the Implementation column, in order to retain only observed costs and remove potential costs (Fig. 1). The resulting entries of both subsets were then selected using matched rows relating to their combined environment, taxonomic group, continent, type of cost, and impacted sector (Supplementary Material 2 and 3). Thus, we only retained cost entries containing the specified combination of these five descriptors in both the Protected Area Subset and in the Non-protected Area Subset, as our interest was to compare PA versus non-PA costs. This resulted in a total of 1,125 expanded and averaged combined entries (531 PA vs 594 non-PA entries), which constitutes the Combined Subset (Subset ii in Fig. 1) and was used to identify descriptors driving differences in costs between protected and non-protected areas.

\section{The protected area WDPA subset}

Observed costs (in the Implementation column) from the Protected Area Subset that were associated with PAs categorized within the WDPA (UNEP-WCMC and IUCN 2020) were considered as the Protected Area WDPA Subset. This resulted in 755 expanded and averaged entries, and this subset was used to understand which descriptors drives costs generated by IAS in PAs (Subset iii in Fig. 1). To do this, we extracted information on four descriptors related to characteristics of the PAs from the WDPA (i.e. PA designation, PA designation year, PA surface area $\left(\mathrm{km}^{2}\right)$, and human development index (HDI)) and four descriptors related to the characteristics of the costs from the InvaCost database (i.e. continent, environment, taxonomic group, and type of cost) (Supplementary Material 2 and 3).

\section{Statistical analyses}

The combined subset: differences in economic costs between protected and non-protected areas

In order to compare differences in the economic costs of IAS between PAs and non-PAs, and to understand which descriptors could affect these differences, we performed a multiple linear regression using the Combined Subset (see Fig. 1). The dependent variable was the average yearly economic cost ( $\log _{10}$-transformed) and the independent variables included a binary $P A$ status factor (i.e. whether the cost pertains to a PA or non-PA) and its two-way interactions with each of the following invasion descriptors: continent, taxonomic group, environment, impacted sector and type of cost (Table 1). This allowed us to assess the differences in the average yearly economic cost between PAs and non-PAs for these descriptors. We only focussed on the interaction effects of PA status with each of these descriptors to explain costs and not on the main effects of the descriptors individually, with the exception of PA status. PA status was evaluated as a main effect in order to quantify the overall difference between PAs and non-PAs. Otherwise, its inclusion as an interaction term allowed for disentangling the contribution of the descriptors driving differences between PAs and non-PAs. Prior to performing this analysis, we assessed that none of the predictors were highly intercorrelated, suggesting the absence of multicollinearity (Pearson's $r<0.65$; Supplementary Material 4). Consequently, all predictors were retained in the analysis. We used the adjusted $\mathrm{R}^{2}$ to assess the percentage of mean annualized economic cost variation that is explained by the models. Significant interactions were assessed using the drop 1 function to obtain Type III sum of squares ANOVA containing p-values from an F-test. Residuals were analyzed using the simulateResiduals function of the 'DHARMa' package version 0.3.3 (Hartig 2020) and 
they satisfied all classical regression assumptions. Additionally, when an interaction factor showed a significant effect, we carried out a post-hoc Wilcoxon Signed Rank test with Holm correction in order to determine which categories were significantly different between PAs and non-PAs.

\section{The protected area WDPA subset: factors affecting costs of invasive alien species across protected areas}

To assess which variables potentially affect the economic costs of IAS across PAs, we performed a multiple linear regression using the data corresponding to the Protected Area WDPA Subset (see Fig. 1). We used the $\log _{10}$-transformed average yearly economic costs as the dependent variable and added $P A$ designation, year of PA designation, PA surface area, human development index, continent, taxonomic group, environment, and type of cost as independent variables. We first excluded incomplete cases (i.e. rows with missing values), and we assessed the correlation among predictors (all predictors were retained in the analysis; Pearson's $\mathrm{r}<0.65$; Supplementary Material 5). We then ran a multiple linear regression, and similar to the previous model, produced the output using the dropl function, assessed residuals (which satisfied all regression assumptions) and tested for differences among categories for the significant factors using the Wilcoxon signed-rank test with Holm corrected p-values.

For each test, when reporting the statistical results of average economic costs, we provide medians and standard deviation because these estimates fairly approximate the mean values of our $\log _{10}$-transformed data and avoid skewed distributions due to cost outliers. All figures were produced in R using ggplot2 (Wickham 2016).

\section{Results}

What are the overall economic costs of invasive alien species in protected areas?

Using the complete dataset (Protected Area Subset), we show that the total reported economic costs in at least 55 PAs (excluding 40 unique references with unspecified PA names) amounted to $\$ 22.24$ billion over the last 46 years (1975-2020). These high costs represent only a fraction of the designated PAs around the world (in total 266,561 terrestrial and marine PAs) suggesting that global PA costs could be several orders of magnitude higher. More specifically, observed costs amounted to $\$ 930.61$ million between 1975-2020 and averaged \$20.23 million annually, while potential costs, as expected, amounted to $\$ 21.31$ billion and averaged $\$ 463.34$ million over the same period (Supplementary Material 6). Both these cost types were generally characterised by an increase over time, with potential costs increasing markedly between 1995 and 2000. Furthermore, observed costs exhibited a gradual increase over time, with reductions in recent years likely due to time lags in cost reporting. The number of entries for both types of costs has been increasing over time, and especially those of observed costs.

PA costs were not distributed homogeneously across continents (Fig. 2a). In particular, Africa reported the greatest share of observed costs (24\%), followed by South America (16\%), North America (15\%), Australasia (15\%), Tropical Asia (14\%), Europe (7\%), Temperate Asia (7\%), Pacific Islands (2\%) and Antarctica (1\%). However, this pattern is quite different when taking into account both observed and potential costs: more costs were reported by PAs located in Australasia (60\%), followed by Europe (36\%) and distantly followed by PAs located in Africa (3\%), Tropical Asia (1\%), North America (0.3\%), and South America (0.1\%). Potential costs were not reported for Antarctica or Temperate Asia. Moreover, most cost occurrences were reported for PAs in Africa (1,287 cost entries) and Europe (1,257 entries), followed by South America (524 entries), Australasia (342 entries), Temperate Asia (332 entries) and North America (222 entries), while the remaining three continents reported less than 200 entries.

In terms of the types of IAS cost incurred by PAs, the majority of observed costs were management focused (i.e. "pre-invasion", "post-invasion", "knowledge and funding" and "mixed management" costs), which totalled $\$ 680.40$ million (73\%), thereby, dominating over damage costs (i.e. $\$ 218.90$ million) (Fig. 2b). Within management costs, "post-invasion" management (i.e. control, eradication, harvesting, management and monitoring) represented the highest proportion of observed costs caused by IAS ( $84 \%$ of management costs). In terms of potential costs, 
(a)

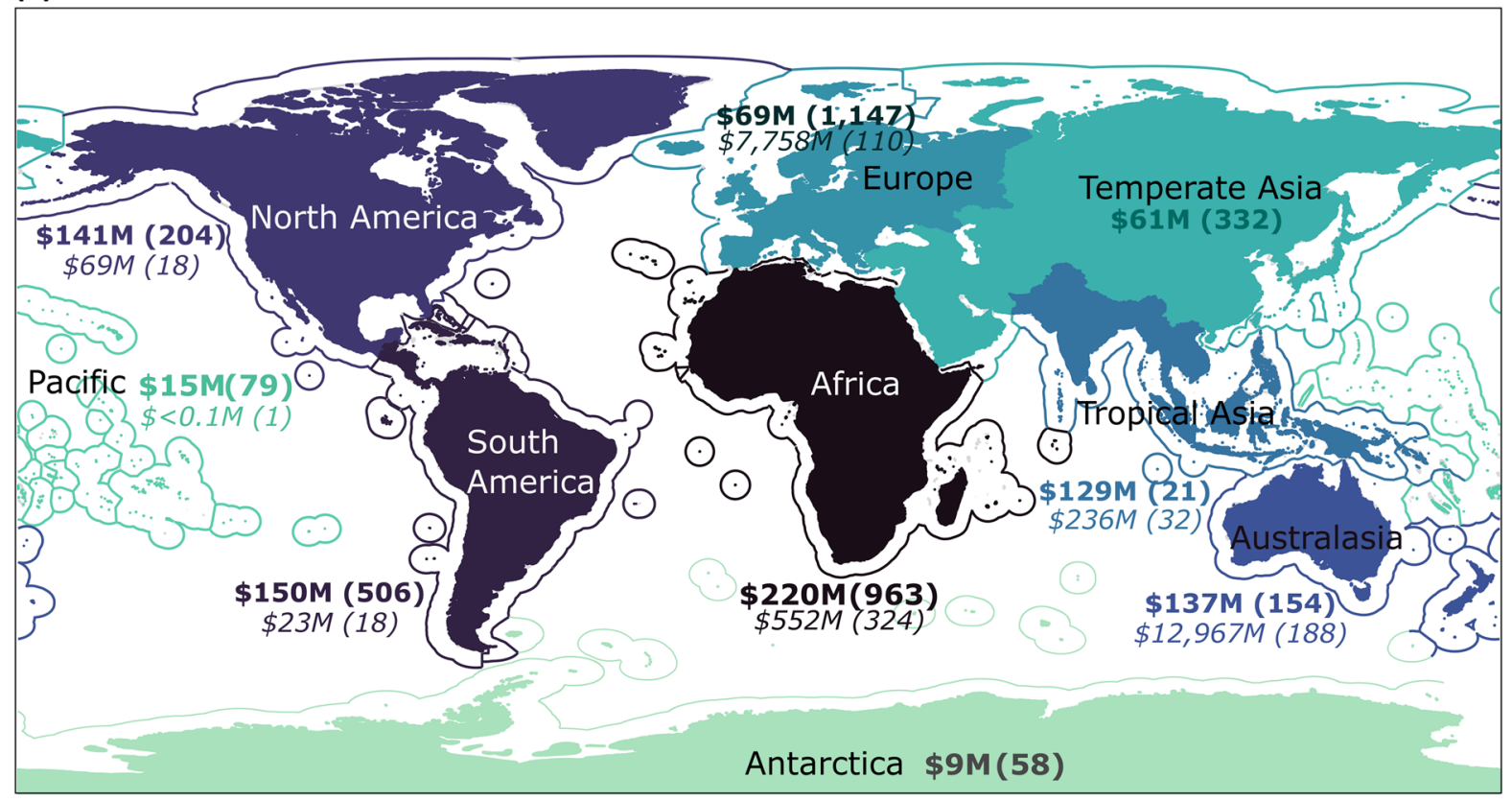

(b)

Breakdown of costs by cost type

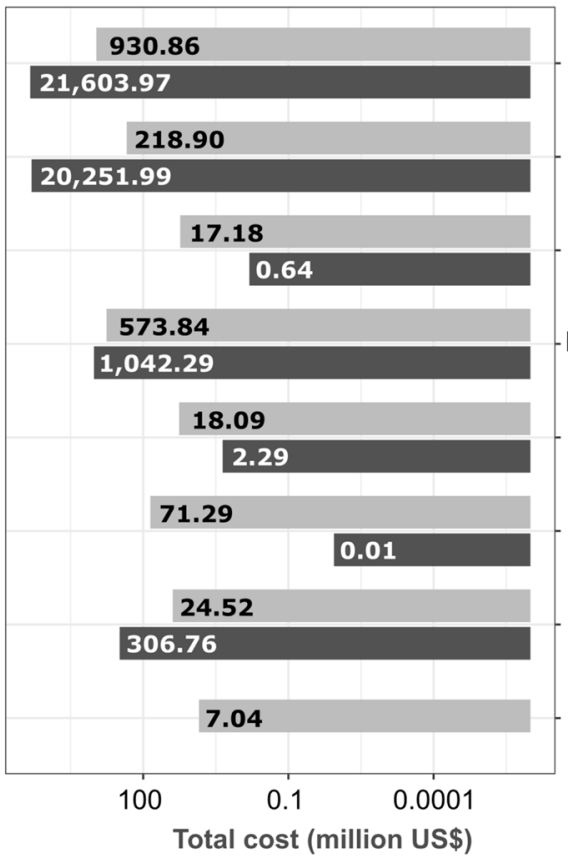

Observed (O) Potential (P)
Proportion of costs by impacted sector

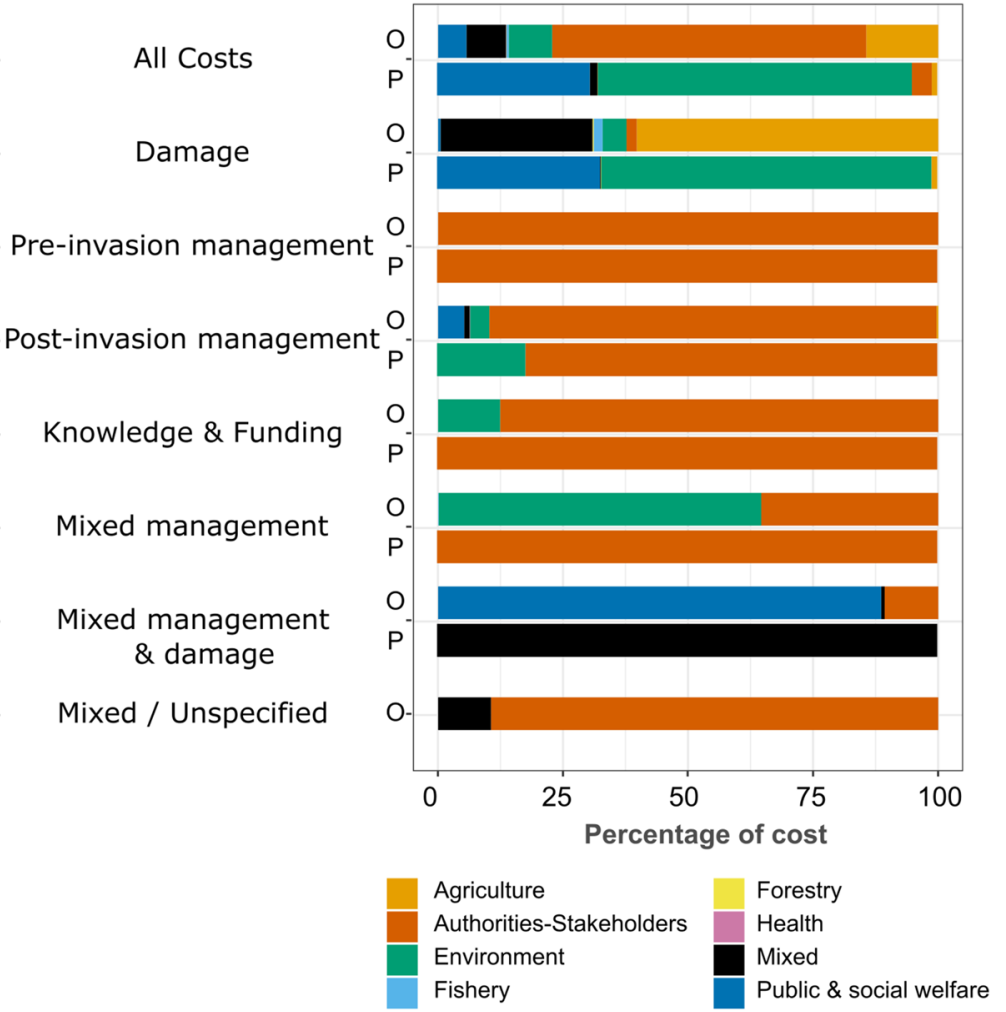


4Fig. 2 Total observed and potential costs of invasive alien species (US\$ million) in protected areas, as well as reported cost entries, presented according to their: a spatial patterns across continents. Colours represent continents together with their associated marine territories. The total observed economic costs are displayed in bold, potential costs are in italics and their corresponding number of cost entries are shown in parenthesis; and b cost type and associated impacted sectors. For the impacted sector, upper bars correspond to observed costs $(\mathrm{O})$ and lower bars to potential costs $(\mathrm{P})$

damage costs constituted the majority (94\%), whilst management costs represented only $5 \%$.

Governmental services and/or official organizations (e.g. conservation agencies, forest services, or associations) that allocate funding for the management of biological invasions ("authorities and stakeholders") reported the highest observed costs (\$584.69 million; 63\%) compared to other sectors (Fig. 2b). This sector accounted for more than $80 \%$ of all types of management costs, except for "mixed management", where it represented $35 \%$ of costs. The "agriculture" and "public and social welfare" sectors sustained the most observed "damage" and "mixed damage and management" costs respectively (60\% and $89 \%$, respectively). The "environment" and "public and social welfare" sectors accounted for $94 \%$ of all potential costs generated by IAS in PAs $(63 \%$ and $31 \%$, respectively) and collectively close to $100 \%$ of damage costs (66\% and 33\%, respectively). "Authorities and stakeholders" accounted for the majority of potential management costs (ranging from 82 to $100 \%$ according to the management type).

Plants dominated the Protected Area Subset with $64 \%$ of the observed cost entries and $79 \%$ of the potential cost entries (Fig. 3). However, the values of observed costs for animals were four times larger than for plants (\$641 vs 172 million, respectively) and potential animal costs were almost 1.5 times larger than for plants (\$13 and 9 billion, respectively). Magnoliopsida (61\% of observed plant costs and $63 \%$ of observed plant entries), Mammalia (43\% of observed animal costs and $50 \%$ of observed animal entries) and Insecta (42\% of observed animal costs and; $15 \%$ of observed animal entries) substantially influenced both costs and number of entries in their respective plant and animal groups.

Specifically, the costliest IAS across PAs comprised mammals (e.g. rats and cats), aquatic plants (e.g. Ludwigia sp.), insects (e.g. mosquitoes and coleopterans: Aedes albopictus, Sternochetus frigidus), and one tree (Prosopis juliflora) (Fig. 4a). With the exception of Ludwigia sp. (the second costliest IAS in our dataset), terrestrial IAS presented higher costs than IAS invading semi-aquatic and aquatic PA environments. The costliest IAS in semi-aquatic and aquatic environments were mainly plants (e.g. Eichhornia crassipes, Baccharis halimifolia, Myriophyllum spicatum), one amphibian (Rhinella marina), one mammal (Castor canadensis), and mosquitoes (Aedes albopictus).

IAS with the highest reported costs differed across continents (Fig. 4b). Reported costs were mostly associated with trees and insects in Africa and Tropical Asia, animals (particularly reptiles, mammals and two invertebrate species) in Temperate Asia; mammals in Australasia; aquatic and semi-aquatic plants, and the insect Vespa velutina in Europe; mammals and plants in South America and the Pacific; and one mammal Sus scrofa, two aquatic plants, and two insects affecting forests in North America.

How do costs differ between non-protected and protected areas?

Using the Combined Subset, we first observed that the reported average observed economic costs caused by IAS did not differ significantly between non-PAs and PAs $(\mathrm{F}=2.72, p=0.100$; Fig. 5a). This could be explained by the skewness of the cost data, reflected by the fact that PAs had a $3 \times$ lower mean cost but a $3 \times$ higher median compared to non-PAs (Supplementary Material 7b). Note that this outcome was a main effect and excluded interaction effects. When looking at the interactions of PA status with the descriptors, two interactions were significant: PA status interacting with the environment and with the continent $(\mathrm{F}=6.88, \quad p<0.001 ; \mathrm{F}=11.02, p<0.001$, respectively; Supplementary Material 7a). The percentage of variance explained by the model was $28.39 \%$ (adjusted $\mathrm{R}^{2}$ ).

In terms of the type of environments and $P A$ status, only terrestrial ecosystems displayed a significant effect with higher costs incurred in PAs compared with non-PAs $(p<0.001$; Fig. 5b; Supplementary Material 7b). Additionally, the total reported IAS cost entries in terrestrial ecosystems accounted for $72 \%$ across all environments. Examining the expenditure for IAS across continents 


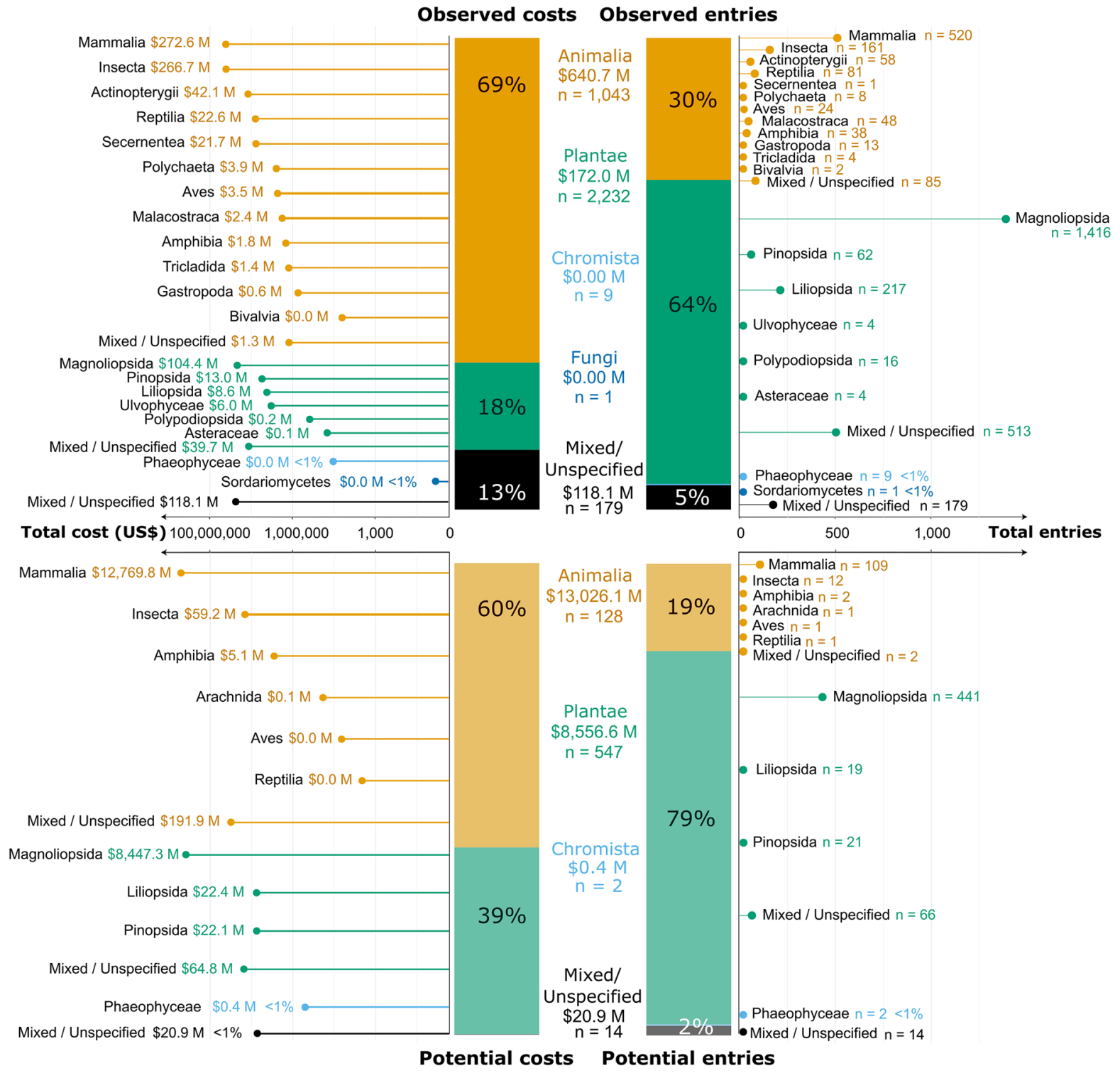

Fig. 3 Taxonomic distribution of cost estimates (US\$ million, left panels) and cost entries (right panel). Coloured bars represent the percentage of costs by kingdoms and lollipops depict total economic costs of the associated classes

and PA status, we found that PA costs incurred in Africa and Temperate Asia were significantly lower compared to costs incurred in non-PAs $(p=0.002$, $p<0.001$, respectively; Fig. 5c; Supplementary Material 7b). Conversely, in Europe, IAS costs were significantly higher in PAs compared to costs incurred in non-PAs $(p<0.001)$.
Which factors influence invasive alien species costs across protected areas?

Using the Protected Area WDPA Subset, we found six descriptors that are important in driving the average yearly observed costs across PAs (three PA descriptors and three cost descriptors): year of designation, 
(a)

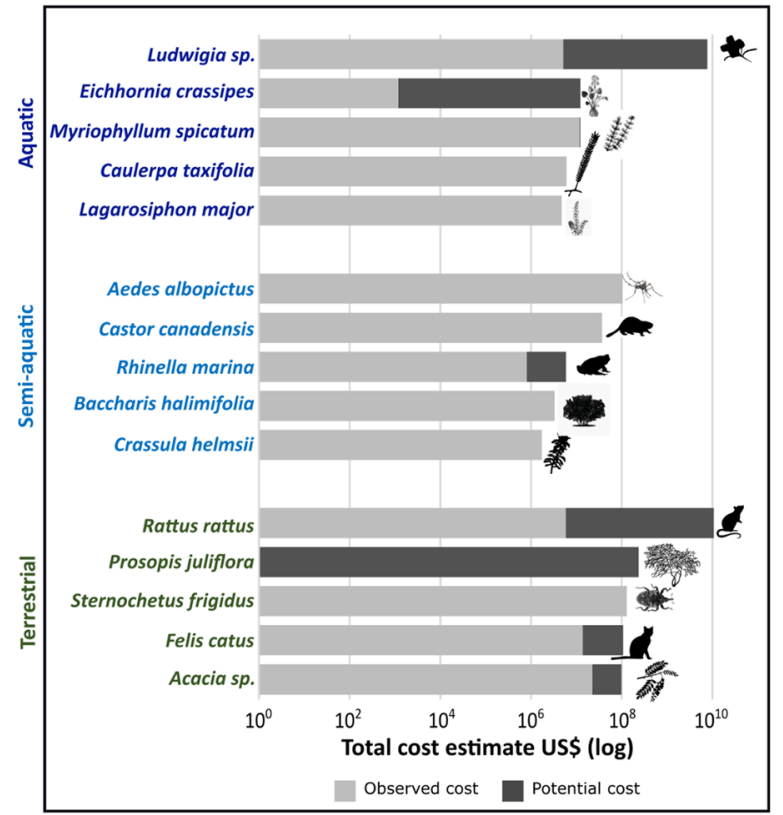

Fig. 4 Bar plot depicting the distinction of observed (light gray) and potential (dark gray) costs in protected areas for the costliest species across a environments and b continents. On the right panel: $\mathrm{AF}=\mathrm{Africa}, \mathrm{AN}=$ Antarctica, $\mathrm{AS}-\mathrm{TE}=\mathrm{Asia}-$

protected area size, human development index, type of environment, continent and taxonomic group; Supplementary Material 8a, b). These descriptors explained $20 \%$ (adjusted $\mathrm{R}^{2}$ ) of the variance.

Costs of IAS in PAs were significantly related to the year of designation and the protected area size. Costs increased in recently designated PAs and with PA size $(\mathrm{F}=8.54, p=0.004 ; \mathrm{F}=5.20, p=0.023$, respectively; Fig. 6a, b). Further, we found a significant positive relationship between the average costs of IAS and the HDI, which represents the (b)

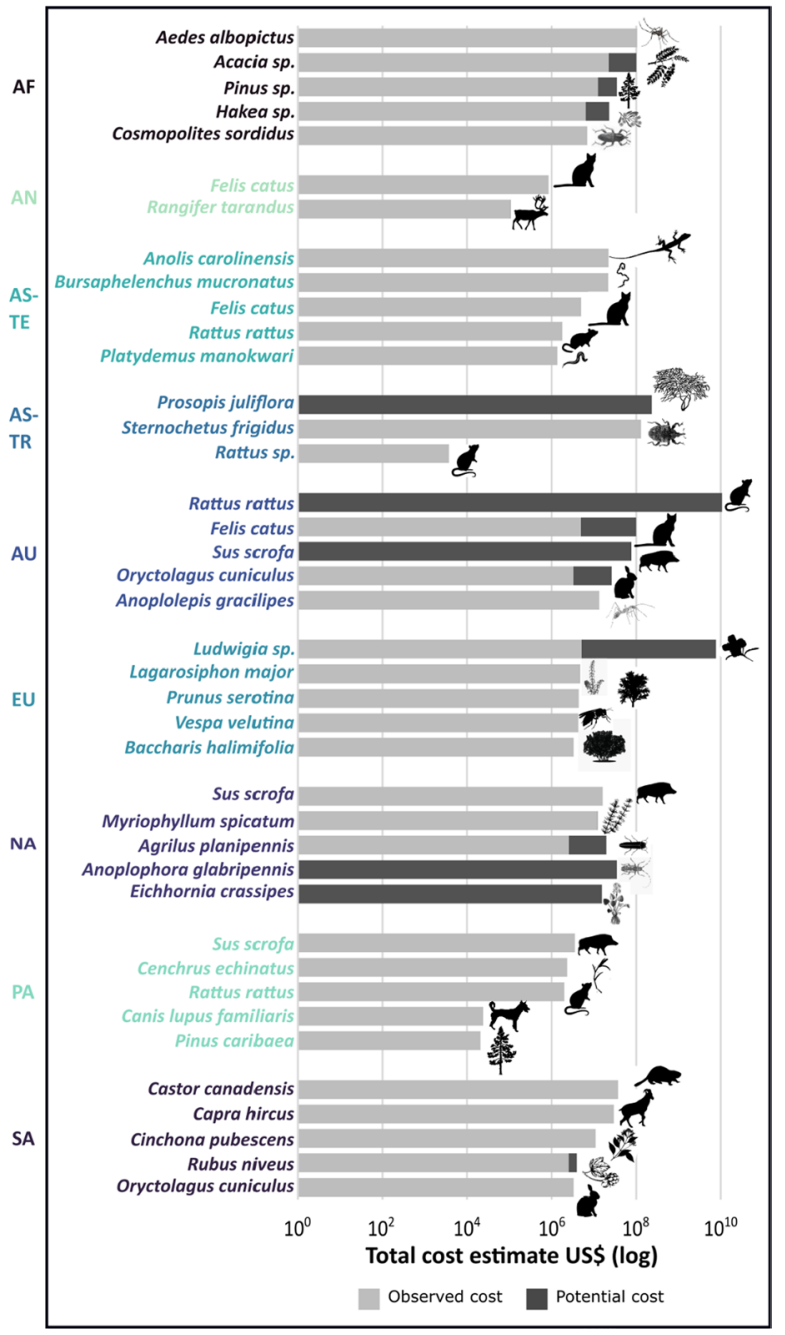

Temperate, $\quad$ AS-TR $=$ Asia-Tropical,$\quad$ AU $=$ Australasia, $\mathrm{EU}=$ Europe, $\mathrm{NA}=$ North America, $\mathrm{PA}=$ Pacific, $\mathrm{SA}=$ South America. Clip arts were obtained from phylopic.org

socio-economic wellbeing of a country $(\mathrm{F}=7.19$, $p=0.008$; Fig. 6c).

Costs in PAs also differed according to the environment $(\mathrm{F}=3.84, p=0.010)$. Terrestrial environments sustained significantly higher costs compared to costs incurred in aquatic environments $(p=0.001)$, while costs in semi-aquatic environments were not significantly different to other environments (Fig. 6d). Moreover, PA costs in terrestrial environments comprised the majority of 
Fig. 5 Distribution of the average economic observed cost estimates ( $\log _{10-}$ scale) incurred by species across: a nonprotected and protected areas; b environments with different land protection statuses; and c continents with different land protection statuses $(\mathrm{NA}=$ North America, $\mathrm{AU}=$ Australasia, $\mathrm{AF}=$ Africa, $\mathrm{PA}=$ Pacific, $\mathrm{AS}-\mathrm{TE}=$ AsiaTemperate, $\mathrm{SA}=$ South America, $\mathrm{EU}=$ Europe). Boxplots display median (line), interquartile range (box) and range (whiskers), and solid circles display outliers. Significant differences between PAs and non-PAs for each category are marked using $p$-values above each boxplot pair, and were tested using a Kruskal Wallis rank sum test for (a) and Wilcoxon signedrank post hoc comparisons for $(\mathbf{b}, \mathbf{c})$. Sample sizes are shown in brackets below each box

reported cost entries (69\%) and incurred $40 \%$ of the total average yearly economic costs.

With respect to the differences in IAS costs regionally, continent was a significant factor ( $\mathrm{F}=4.69, p<0.001$; Fig. 6e). Specifically, costs in European PAs were only similar to South American PAs and differed significantly to all other groups. In turn, Africa and South America were significantly different to Australasia, Pacific Islands and Antarctica. Additionally, South America significantly exceeded Temperate Asia and North America. Further, Africa and South America incurred the majority of the total average yearly economic costs $(40 \%$ and $28 \%$, respectively), followed by Australasia (10\%), Europe (8\%), North America (7\%), Pacific Islands (4\%), Temperate Asia (2\%) and Antarctica (1\%) (Fig. 6e). Despite the highest reported costs incurred in African PAs, the reported number of cost entries are not congruent (12\% of all cost entries). On the contrary, European PAs incurred much lower costs despite having the highest number of reported costs ( $41 \%$ of all cost entries). Lastly, since the effect of continents among covariates is context-dependent, this suggests that the overall effects of spatial distribution on the magnitude of costs is significantly affected by IAS (Supplementary Material 8a, b).

Average yearly economic costs in PAs also differed significantly with respect to different taxa $(F=4.54$, $p=0.004$; Fig. 6f). Costs were similar between invertebrates and vertebrates $(p=0.368)$ but these groups incurred significantly higher costs than plants ( $p=0.001 ; p<0.001$, respectively). Surprisingly, even though more costs were reported for plants $(49 \%$ of cost entries), they incurred the lowest total costs (4.6\% of the average yearly economic costs).
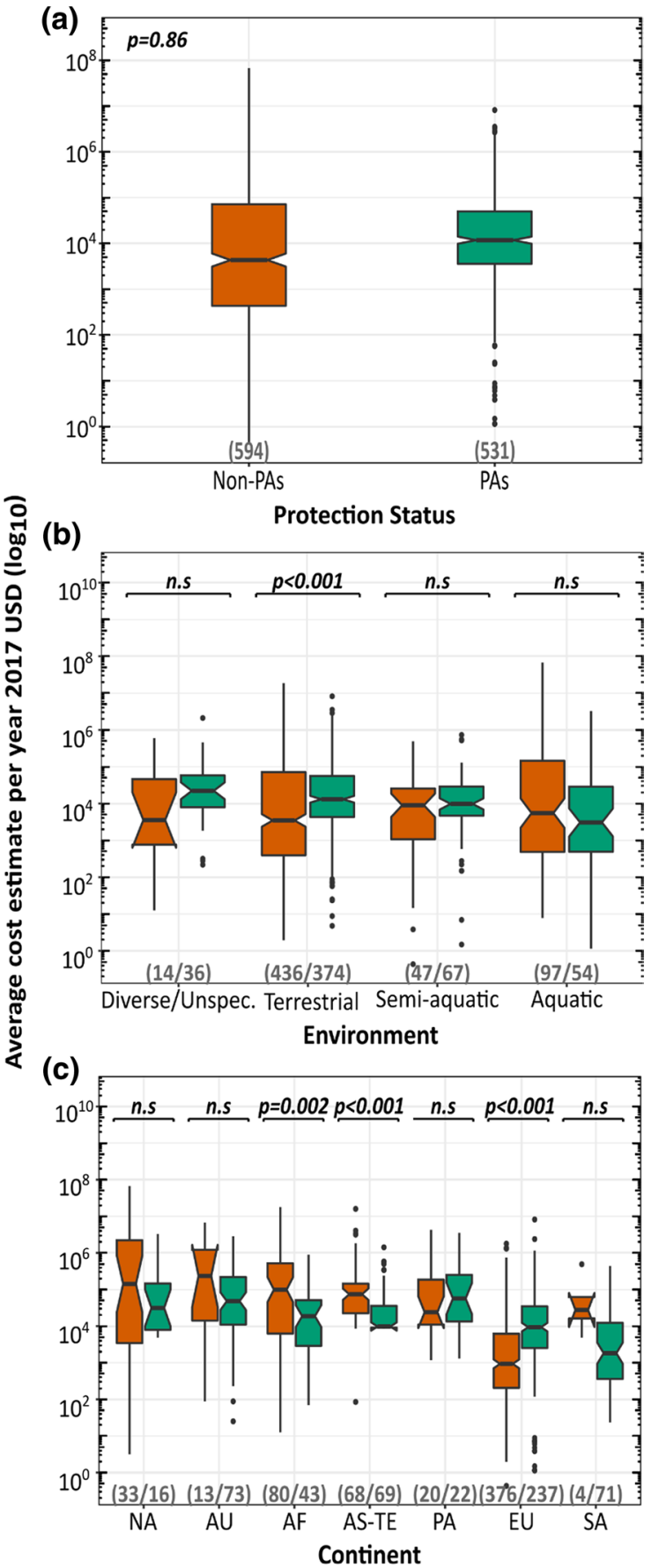

\section{Discussion}

Where do we stand?

This study provides the first comprehensive compilation and analysis of reported costs of biological 
invasions in PAs around the world, which amounts to $\$ 22.24$ billion over the last 46 years (1975-2020). Our results partially confirm our expectations that costs of IAS in PAs are (i) high, but predominantly comprise management costs (nonetheless, the proportion of damage costs was higher than expected); (ii) different between PAs and non-PAs, but only within certain continents and environments; and (iii) driven by factors linked to both the invasion costs and PA characteristics. Firstly, we showed that the highest number of reported entries was in Europe but the highest observed costs from invasions in PAs were found in Africa. These costs were caused primarily in terrestrial environments and caused mainly by mammals and insects (and surprisingly to a lesser extent by flowering plants, though more cost entries were reported for plants). Most observed costs were incurred post-invasion and largely affected PA authorities and stakeholders. Secondly, we found that, in general, mean invasion-related costs in PAs were globally similar compared to matched costs in non-PAs. However, per unit of area, costs are higher in PAs (costs in PAs represent $20 \%$ of the total cost, when the combined area for which we have PA costs is equivalent to $\sim 0.3 \%$ of the total global PAs), even though we expected the opposite due to PAs consisting of less monetized assets and less disturbances (such as agriculture, infrastructure, human population density, etc.). Nevertheless, costs in PAs were significantly higher than non-PAs only in Europe and terrestrial environments. Thirdly, we found that the costs of IAS also increased in PAs that were recently designated, are larger in size and those located in countries with a higher HDI. These results highlight already burgeoning but growing economic impacts of biological invasions in PAs, despite pervasive knowledge gaps at geographic, taxonomic and sectoral scales, context-dependencies and challenges to cost estimation and collation.

\section{Taxonomic bias}

Our study, like many others in invasion science, reflects a strong taxonomic bias, in terms of economic costs, research effort and taxonomic awareness (Pysek et al. 2008; Rico-Sánchez et al., 2020). Invasive predatory mammals are largely known to have the most devastating effects on biodiversity worldwide (Doherty et al. 2016; Liu et al. 2020). This aligns with findings in this study that mammals are the costliest to manage in PAs, and is similar to patterns within PAs of other countries (see for example Rico-Sánchez et al. 2021 in Mexico or BallesterosMejia et al. 2021 in Ecuador). Further, in line with the suggestions of Pyšek et al. (2008) indicating that invasive invertebrates were abundantly studied, we found that insects were among the costliest species in PAs. These costs were mostly driven by the mango pulp weevil (Sternochetus frigidus; primarily costs incurred in a Palawan game refuge and bird sanctuary), followed by the Asian tiger mosquito (Aedes albopictus). The high investment in controlling this weevil is likely due to mango, the third most important fruit crop in the Philippines. Mosquitoes pose a significant threat to humans, as they can serve as vectors of pathogens which can lead to the spread of diseases (Schaffner et al. 2013). In this study, the high expenses for the Asian tiger mosquito were incurred in the Réunion National Park, which is not surprising since this species has become a major human health concern across the island of Réunion (Latreille et al. 2019).

Although we found that plants are managed more often in PAs (as shown by the highest proportion of reported cost entries in the Protected Area WDPA Subset; 49\%), their reported observed costs are substantially lower than those of either mammals or insects. Among plants, flowering taxa accrued the highest reported expenses, with most costs associated with aquatic plants (Ludwigia sp. and all incurred in France; Dandelot et al. 2008) and trees (Acacia sp.). Globally, invasive plants, specifically trees, have significant (and growing) impacts on the environment and the economy (Richardson and Rejmánek 2011; Hirsch et al. 2017). Plants are generally studied more than other taxonomic groups (Pysek et al. 2008; Warren II et al. 2017) and successfully dominate many ecosystems (Pyšek et al. 2017). However, plant invasion management is notoriously difficult and high management costs can be associated with plant control and/or eradication (Gardener et al. 2010), due to for example, persistent seed banks (Gioria et al. 2012; Strydom et al. 2017), or limited effective management of aquatic plants (e.g. submerged macrophytes; Hussner et al., 2017; Coughlan et al., 2020). Furthermore, failed control attempts may not be reported, potentially distorting the true magnitude of damage costs and management expenditure (Zenni and Nuñez 


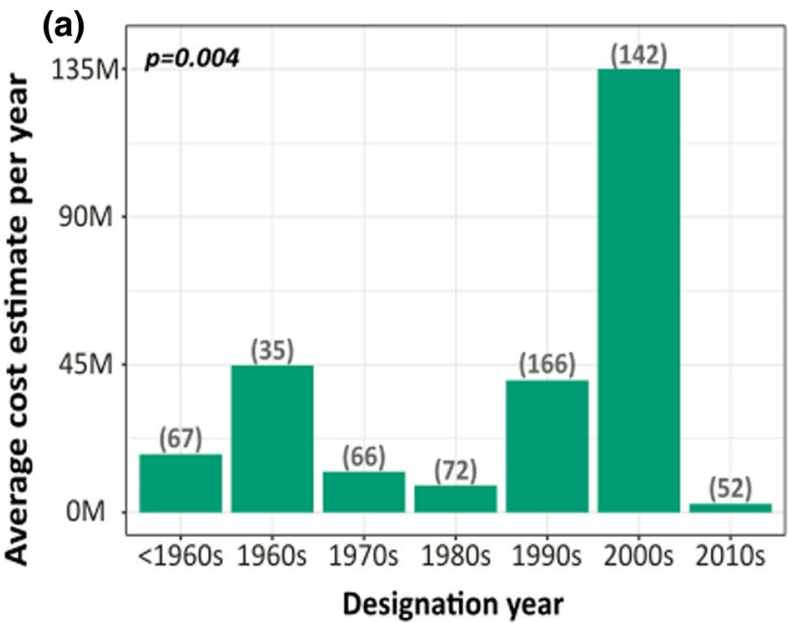

(c)

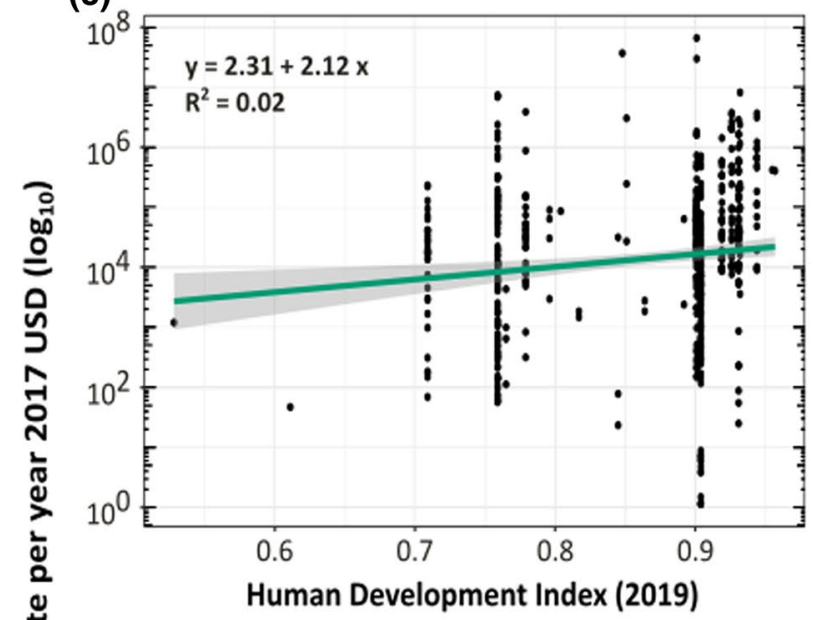

(e)

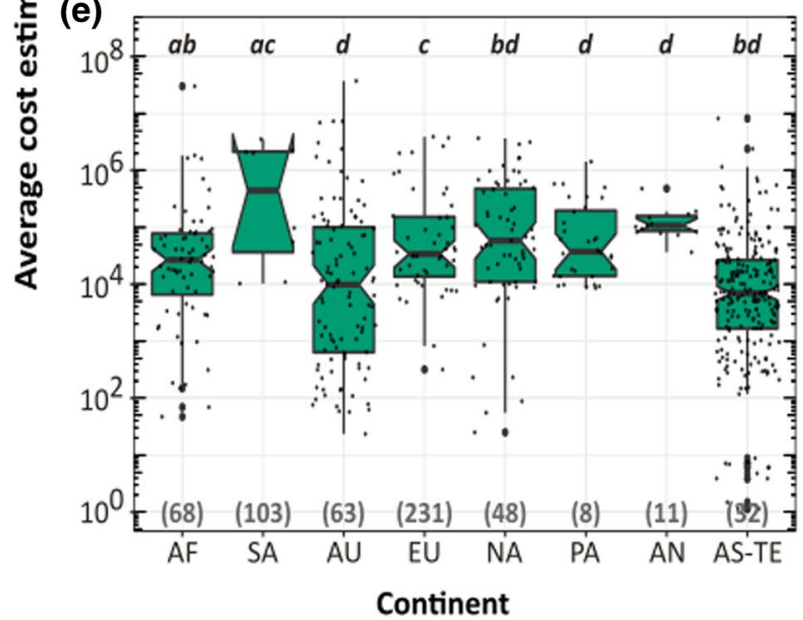

2013). This highlights the importance of long-term control efforts, as well as inclusive reporting of all invasion costs.

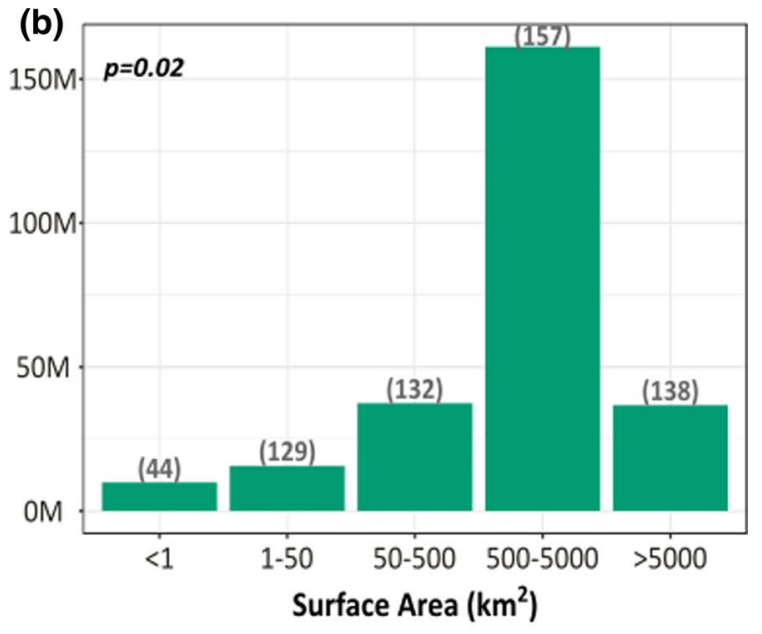

(d)
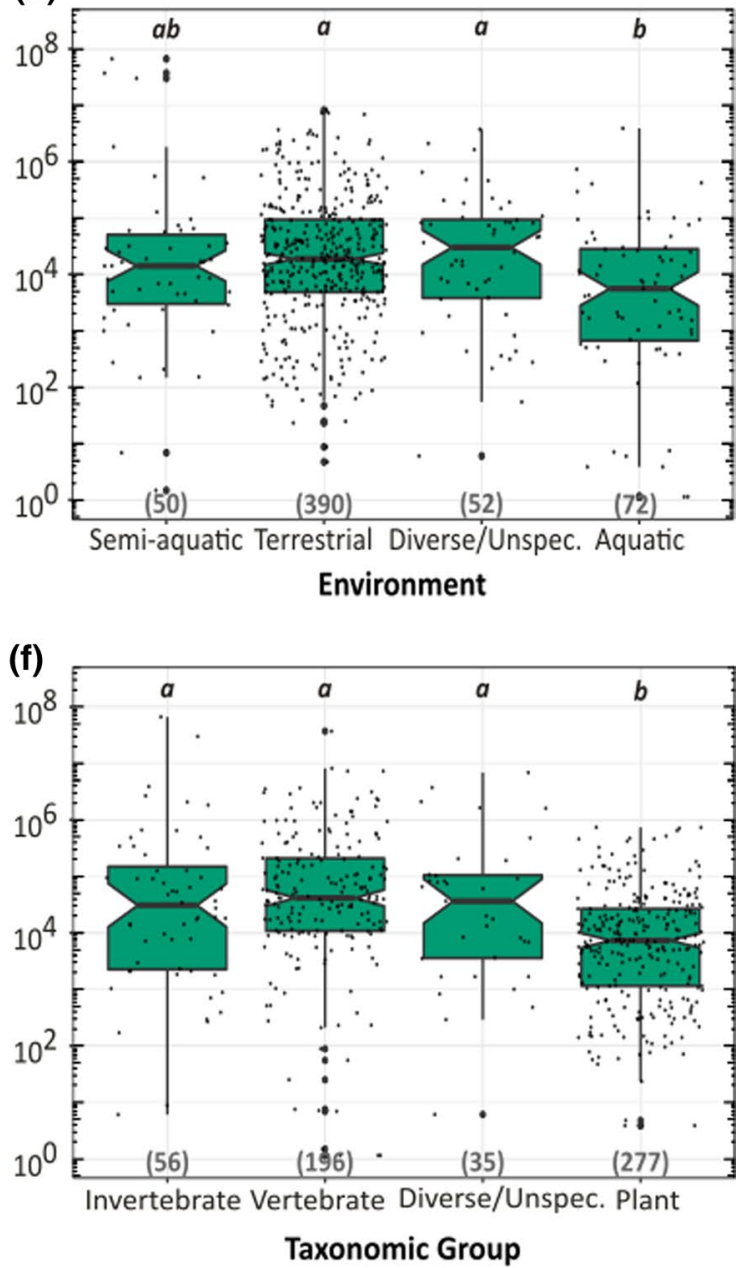

Looking at the type of costs associated with these species, it is apparent that the prevalent management focus on mammals (pigs and rats), insects (mango 
4Fig. 6 The relationship between the average observed economic costs and a the year in which the PA was designated (y-axis in US\$ million); $\mathbf{b}$ the size of the PA (y-axis in US\$ million); $\mathbf{c}$ the invaded countries' HDI; $\mathbf{d}$ the environment in which the taxa causing impact in PAs are located; e the continent in which the impacted $\mathrm{PA}$ is located $(\mathrm{AF}=$ Africa, $\mathrm{SA}=$ South America, $\mathrm{AU}=$ Australasia, $\mathrm{EU}=$ Europe, $\mathrm{NA}=$ North America, $\mathrm{PA}=$ Pacific,$\quad \mathrm{AN}=$ Antarctica, AS-TE = Asia-Temperate); and $\mathbf{f}$ the taxonomic group of the invasive alien species. In (a) and (b) the data were categorized for better visualization, but in the model these variables were fitted as continuous variables. Categories with different letters show significant differences among them, which were tested using the Wilcoxon signed-rank test. For the boxplots, the solid line shows the median, the lower and upper hinges of the box represent the lower and upper quartiles, the whiskers indicate the range of the data, solid circles are outliers, and solid squares depict the observed data points. Sample sizes are in brackets below each box

weevil) and plants (water primrose) in PAs is mostly a result of their associated damage costs (i.e. damage was the second highest type of observed cost reported after post-invasion management). In this regard, it is important to emphasize that our cost data predominantly relate to economic rather than ecological effects. However, the costliest species economically might not be the most ecologically harmful. Given ecological impacts of biological invasions are seldom monetized due to their indirect nature, it is important to bear in mind that our data are inherently taxonomically biased towards IAS that incur economic cost, either through management, or damages to primary sectors such as agriculture and fisheries. While evidence for economic impacts should not underpin investments to safeguard biodiversity from global change pressures, our results provide broad scale incentives for better management within PAs to contain and prevent both current and future IAS.

\section{Geographical bias}

IAS research in PAs has shown to be geographically biased towards the Americas and Pacific Islands while less frequently studied regions include Europe, Africa and Asia (Hulme et al. 2014). However, conversely, we show that observed costs are more frequently reported in Europe, Africa and South America, respectively, while cost reporting for PAs in the Pacific Islands is considerably lagging. Highest cost reporting in Europe may firstly be explained as an artefact of the available literature as well as greater opportunities to study invasions across different contexts (e.g. landforms, islands, peninsulas and climates), especially since Europe contains the highest number of PAs worldwide $(n=158,450$; UNEP-WCMC and IUCN 2020). Secondly, the implementation of the European Union's Natura 2000 PA network, the largest coordinated network of PAs globally, may have contributed to shaping this pattern (European Environmental Agency 2012), which could be supported by a concomitance between an increase in the cost data recorded in our database and the establishment of the Natura 2000 PA network since the early 1990s. Overall, geographic unevenness in cost reporting might also reflect differences in economic output among countries, because GDP is predictive of economic damages by IAS as well as investments towards management (Haubrock et al., 2021). Accordingly, countries with a higher GDP may be more likely to invest in managing IAS in PAs, conduct research on IAS impacts, and/or designate and conserve PAs more broadly.

We identify marked gaps in the spatial distribution of our complete dataset (i.e. subset i). According to the number of PAs classified in the WDPA dataset, our complete dataset reports PA costs from only $0.3 \%$ of the PAs in Africa, $0.3 \%$ in South America, 0.1\% in North America, $0.1 \%$ in Asia and the Pacific, and $0.03 \%$ in Europe. This substantial underrepresentation across space further highlights that the high costs presented here represent a very small fraction of the real economic burden of invasions in PAs. Despite these knowledge gaps and greater cost reporting in Europe, African and South American PAs incurred greatest total observed costs - probably an artefact of spatial representation in our data (e.g. Africa and South America had ten times more PA coverage in InvaCost than Europe). The majority of recorded costs in Africa were accrued in South Africa (i.e. Western Cape Province and Kruger National Park), a leader in invasion biology research with a long history of (i) conservation efforts (van Wilgen et al. 2020), as an example, through substantial investments in IAS management in the Western Cape by the South Africa's Natural Resource Management Programmes (van Wilgen et al. 2010) and (ii) research effort in invasion biology (Richardson et al. 2020), stimulated for example by the highest number of IAS in the Kruger National Park where control efforts have taken place since the 1950s (Foxcroft and Freitag-Ronaldson 
2007; Foxcroft et al. 2017b). In South American PAs, most research investment, as reflected by the high observed total costs, largely occurred in the Galápagos Islands, Ecuador, where IAS are the biggest biodiversity threat (Trueman et al. 2010). Consequently, the high economic costs reported on these islands may be the result of intensive management activities (Gardener et al. 2010, 2013), as well as the importance of the Galápagos Islands to both biological research and tourism (Ballesteros-Mejia et al. 2021).

These trends may additionally be influenced by differential cost reporting practices among regions, with many countries evidently lacking in their cost reporting efforts. Therefore, our results must be interpreted in the context of the available data and may change as further costs become available. Given the differences in PA designations, further research should be conducted at the country-scale, particularly because PAs are not uniformly classified across the world. Here, we coarsened our analyses to the global scale to avoid (i) insufficient sample size for some regions which would have been otherwise removed from our analyses; (ii) making dubious assumptions on potential uniformness in PA designation within each continent; and (iii) counteracting the global-scale approach adopted throughout this study. Consequently, our study should be seen as a starting point for further investigation at finer scales, which will allow more specific conclusions to be drawn and provide contextbased recommendations.

\section{Methodological bias}

Sporadic cost reporting for PAs, as evidenced both by our data and the literature at large, points to a lack of reporting structures, mechanisms and/or incentives for tracking invasion costs, and/or methodological expertise for monetary quantifications (Diagne et al. 2020a; Robertson et al. 2020). Nevertheless, costs in PAs have steadily increased over time, both in terms of magnitude and numbers of reported cost entries. A vast majority of costs in PAs emanate from predictions, models or simulations (i.e. "potential" costs in the database) and therefore further work is needed, wherever possible, to capture and report actual invasion costs on the ground.

One potential reason for the apparent methodological bias could be the result of language barriers that have so far precluded the capturing of cost data.
While InvaCost has compiled cost information in both English and 15 non-English languages (Angulo et al., 2021), countries with language barriers for capturing data still remain, which most likely contributed to the unevenness presented in this study. Ultimately, data collection can result in biased information which can significantly impact outcomes. InvaCost is a dynamic database, limited by available and accessible electronic literature, and will grow and be updated over time. Our study only provides a snapshot of a 'living' database, focusing on PAs, and therefore the results need to be interpreted cautiously. We note that data were not available to account for different proportions of IAS with reported costs and their respective abundances among contexts, despite the importance of abundances in impact prediction (Parker et al., 1999; Dick et al., 2017). Nonetheless, we believe that given the most up-to-date information on the monetary cost in PAs, this study stresses that more should be invested in the management of IAS to realise the role of PAs and achieve long term conservation of nature. The collection of PA cost data through the use of tailored surveys (e.g. focused on IAS management costs and challenges) which targets PA managers will be instrumental in this context. This will facilitate the collection of scarce and/or inaccessible information, which ultimately helps to implement concerted and evidence-based recommendations.

Drivers of invasive alien species costs in protected areas

The present study found overall similarities in costs between PAs and non-PAs, with differences conserved within particular continents (i.e. Africa, Temperate Asia and Europe) or environments (i.e. terrestrial). This finding is surprising for several reasons. Firstly, PAs only cover up to $23.6 \%$ of the planet's surface (www.protectedplanet.net, October 2021). As such, we expected that much higher investments would be made for IAS outside PAs. Land use and other impacts outside PAs significantly influence species and ecosystems within PAs (Foxcroft et al. 2011; Liu et al. 2020), and therefore managing IAS outside PA networks is necessary to ensure effective conservation within PA networks. Nevertheless, although we matched PA and non-PA costs according to their environment, taxonomic group and continent, this does not mean that these non-PAs and PAs are 
ecologically connected. In addition, PAs are likely to be subject to reduced anthropogenic activity with less human-made infrastructure or economic activities that can be damaged or degraded by invasions compared to non-PAs. This is either because PAs have been established in relatively pristine areas or because their protection status inherently limits economic activities. Therefore, non-PAs are more likely to incur resource damage or loss costs, whereas PAs are more likely to incur management costs. Moreover, the unmatched costs (hence those not analysed) under our criteria are likely related to damage costs in nonPAs (Haubrock et al., 2021) and management costs within PAs (Rico-Sánchez et al., 2021). Therefore, we expect our trends to correspond with these additional data.

Our results show that the HDI influenced the economic costs of IAS in PAs. This positive effect between the degree of wealth and conservation decisions is likely due to developed countries having the ability to better document damage costs, and most importantly having more means to manage IAS (Nuñez and Pauchard 2010). In addition, for most developing countries, the primary goal of economic growth does not always go hand in hand with conservation goals. Consequently, major environmental problems, such as biological invasions, continue to be a challenge in countries with fragile economies (Early et al. 2016). Further, invaders from terrestrial and semi-aquatic environments have the highest reported costs while aquatic taxa have the lowest. The high costs associated with terrestrial species in this study are driven by both vertebrates (particularly mammals) and invertebrates (particularly insects). In contrast, high semi-aquatic costs are most likely driven by mosquitoes (which go through an aquatic life stage) and this can lead to high health costs. The low costs for aquatic species are likely due to the cryptic nature of submerged environments and the respective difficulty in managing their invasive populations (e.g. aquatic macrophytes), compounded by research bias towards terrestrial systems (Cuthbert et al. 2021).

\section{Overcoming management challenges in protected} areas

The control and eradication of IAS in PAs are timeand resource-consuming, and prioritization schemes are necessary in light of limited available budgets for conservation (Ziller et al. 2020). Information on the costs of IAS can serve as valuable input to priority-setting schemes aimed at managing biological invasions in PAs. This becomes even more important given that most countries have a limited capacity to effectively respond to invasions (McCarthy et al. 2012; Early et al. 2016; Faulkner et al. 2020), and decisions about resource allocation for biosecurity, control and post-invasion management are thus often made on an ad hoc basis (Epanchin-Niell 2017; Liebhold and Kean, 2019; Kourantidou and Kaiser 2021). Knowledge of IAS economic costs is key to help PA managers invest in efforts that optimize large scale positive results at the lowest possible cost (Gallardo and Aldridge 2013). We observed that $73 \%$ of incurred IAS costs in PAs were management costs allocated by governmental agencies for the management of IAS or environmental impact costs.

Lower expenditure on pre-invasion than post-invasion management suggests that management strategies are more reactive than proactive and indicates that management costs are much higher than prevention costs. This pattern may extend beyond PAs, as this type of reactive management has also been noted in non-PAs of Central and South America (Heringer et al. 2021). Further, the dominance of post-invasion management expenditure points to the need for more preventative measures, such as biosecurity, to curtail the increased expenses associated with post-invasion management (Leung et al. 2002; Ahmed et al. 2021). Given that preserving biodiversity is one of the main goals of PAs (although in some cases goals are combined with others depending on the management category of the PA; see https://www.iucn.org/theme/ protected-areas/about/protected-area-categories), preinvasion management is seen as essential to avoiding the myriad impacts of IAS on native species and ecosystems.

\section{Perspectives on underestimated costs}

While biological invasions continue to increase, the efficacy of PAs in conserving biodiversity remains limited (Rodrigues et al. 2004; Liu et al. 2020). Generally, the effectiveness of management can differ markedly across PAs, with just $22 \%$ of PAs recognized as having "sound management" (Leverington et al. 2010). Ineffective management of these so-called "paper parks" (i.e. parks in name 
only which provide little or no protection) mainly stems from a lack of investment. This is the case of many PAs from developing countries due to chronic financial deficits (James et al. 1999; Wilkie et al. 2001; Gill et al. 2017; Lindsey et al. 2018). Balmford et al. (2002) suggested yearly investments of approximately $\$ 45$ billion (over 30 years) to efficiently maintain an expanded network of tropical PAs covering $15 \%$ of terrestrial and $30 \%$ of marine ecosystems; a study by McCarthy et al. (2012) put forward that $\$ 76$ billion per year is needed to conserve terrestrial PAs globally; Balmford et al. (2004) proposed that it would cost \$5-19 billion per year to conserve 20-30\% of marine ecosystems globally; and finally, Lindsey et al. (2018) suggested that \$1-2 billion per year are required to conserve African PAs with lions. PAs in developing countries generally receive significantly less funding than that required for basic conservation management (James et al. 1999; Bruner et al. 2004). Our results reveal that although PAs in continents such as Africa and South America reported higher costs, they do not equivalently invest in IAS management. However, since limited cost data was available for PAs ( $\sim 0.3 \%$ of PAs), this suggests massive underestimation of economic costs in PAs globally. Further, the taxa highlighted in this paper, as well as the number of reported entries, indicate that current reporting of IAS costs in PAs is greatly underestimated.

PAs serve as the backbone of global conservation and biological invasions are a key driver of change in PAs (Foxcroft et al. 2017a; Shackleton et al. 2020a, b). Our study shows that many IAS have already caused significant management and damage costs across all environments and continents. If not managed resourcefully, their impacts can only be expected to intensify, thus lowering the biodiversity preservation goal of PAs. Globally, the number of IAS are expected to increase as more species are introduced via global trade and more invasions are discovered as a result of invasion debt (Essl et al. 2011; Seebens et al. 2017, 2020). As such, we strongly encourage comprehensive economic estimations and reporting of IAS costs across PAs in order to improve invasive species management. This will provide an opportunity to maximize return on conservation investments which will have a significant impact on biodiversity outcomes in PAs.
Funding The authors acknowledge the French National Research Agency (ANR-14-CE02-0021) and the BNP-Paribas Foundation Climate Initiative for funding the InvaCost project that allowed the construction of the InvaCost database. The present work was conducted following a workshop funded by the AXA Research Fund Chair of Invasion Biology and is part of the AlienScenarios project funded by BiodivERsA and Belmont-Forum call 2018 on biodiversity scenarios. DM and $\mathrm{AN}$ are funded by Grant No. 18-18495S, EXPRO Grant 19-28807X (Czech Science Foundation) and long-term research development project RVO 67985939 (Czech Academy of Sciences). RNC acknowledges funding from the Alexander von Humboldt Foundation. EA's contract comes from the AXA Research Fund Chair of Invasion Biology of University Paris Saclay. CD is funded by the BiodivERsA-Belmont Forum Project "Alien Scenarios" (BMBF/PT DLR 01LC1807C). GH is supported by Coordenação de Aperfeiçoamento de Pessoal de Nível Superior - Brasil (Capes). DR is funded by the BiodivERsA 'ASICS' project (ANR-20-EBI5-0004, BiodivClim call 2019-2020), the French Polar Institute Paul-Emile Victor (Project IPEV 136 'SUBANTECO'), and the long-term research network on biodiversity in Antarctic and sub-Antarctic ecosystems (Zone Atelier InEE-CNRS Antarctique et Terres Australes). JFL's travel funding to attend the Invacost workshop was provided by the Auburn University School of Forestry and Wildlife Sciences.

Availability of data and material All data used are available in the Supplementary Material (ESM_3).

Code availability Not available.

\section{Declarations}

Conflict of interest The authors declare that there is no conflict of interest.

Ethics approval Not applicable.

Consent to participate Not applicable.

Consent for publication All authors have read and approved the submitted version of the manuscript.

Open Access This article is licensed under a Creative Commons Attribution 4.0 International License, which permits use, sharing, adaptation, distribution and reproduction in any medium or format, as long as you give appropriate credit to the original author(s) and the source, provide a link to the Creative Commons licence, and indicate if changes were made. The images or other third party material in this article are included in the article's Creative Commons licence, unless indicated otherwise in a credit line to the material. If material is not included in the article's Creative Commons licence and your intended use is not permitted by statutory regulation or exceeds the permitted use, you will need to obtain permission directly from the copyright holder. To view a copy of this licence, visit http://creativecommons.org/licenses/by/4.0/. 


\section{References}

Ahmed DA, Hudgins EJ, Cuthbert RN et al (2021) Modelling the damage costs of invasive alien species. Biol Invasion. https://doi.org/10.1007/s10530-021-02586-5

Angulo E, Diagne C, Ballesteros-Mejia L et al (2021) NonEnglish languages enrich scientific knowledge: the example of economic costs of biological invasions. Sci Total Environ 775:144441

Bailey SA, Brown L, Campbell ML et al (2020) Trends in the detection of aquatic non-indigenous species across global marine, estuarine and freshwater ecosystems: A 50-year perspective. Divers Distrib 26:1780-1797. https://doi.org/10.1111/ddi.13167

Ballesteros-Mejia L, Angulo E, Diagne C, et al (2021) Economic costs of biological invasions in Ecuador: the importance of the Galapagos Islands. In: Zenni RD, McDermott S, García-Berthou E, et al (eds) The economic costs of biological invasions around the world. NeoBiota 67: 375-400. https://doi.org/10.3897/neobi ota.67.59116

Balmford A, Bruner A, Cooper P et al (2002) Economic reasons for conserving wild nature. Science 297:950-953

Balmford A, Gravestock P, Hockley N et al (2004) The worldwide costs of marine protected areas. Proc Natl Acad Sci USA 101:9694-9697. https://doi.org/10. 1073/pnas.0403239101

Bruner AG, Gullison RE, Balmford A (2004) Financial costs and shortfalls of managing and expanding protected-area systems in developing countries. Bioscience 54:1119-1126. https://doi.org/10.1641/00063568(2004)054[1119:fcasom]2.0.co;2

Butchart SHM, Walpole M, Collen B et al (2010) Global biodiversity: indicators of recent declines. Science 328:1164-1168. https://doi.org/10.1126/science.11875 12

Chape S, Harrison J, Spalding M, Lysenko I (2005) Measuring the extent and effectiveness of protected areas as an indicator for meeting global biodiversity targets. Phil Trans R Soc B 360:443-455. https://doi.org/10.1098/ rstb.2004.1592

Charles H, Dukes JS (2008) Impacts of invasive species on ecosystem services. In: Nentwig W (ed) Biological invasions. Springer, Berlin

Conn DB (2014) Aquatic invasive species and emerging infectious disease threats: a one health perspective. Aquat Invasion 9:38-390

Coughlan NE, Cuthbert RN, Dick JTA (2020) Aquatic biosecurity remains a damp squib. Biodivers Conserv 29:3091-3093. https://doi.org/10.1007/ s10531-020-02011-8

Cuthbert RN, Pattison Z, Taylor NG et al (2021) Global economic costs of aquatic invasive alien species. Sci Total Environ 775:145238

Dana ED, Jeschke JM, García-de-Lomas J (2014) Decision tools for managing biological invasions: existing biases and future needs. Oryx 48:56-63

Dandelot S, Robles C, Pech N et al (2008) Allelopathic potential of two invasive alien Ludwigia spp. Aquat Bot 88:311-316
Daněk J, Vačkář D, Krkoška Lorencová E (2017) Value of ecosystem services in protected landscape areas in the Czech Republic. Beskydy 10:99-112

Diagne C, Catford JA, Essl F, Nuñez MA, Courchamp F (2020a) What are the economic costs of biological invasions? A complex topic requiring international and interdisciplinary expertise. NeoBiota 63:25-37. https://doi. org/10.3897/neobiota.63.55260

Diagne C, Leroy B, Gozlan RE et al (2020b) InvaCost, a public database of the economic costs of biological invasions worldwide. Sci Data 7:277. https://doi.org/10.1038/ s41597-020-00586-z

Diagne C, Leroy B, Vaissière A-C et al (2021) High and rising economic costs of biological invasions worldwide. Nature 592:571-576

Dick JT, Laverty C, Lennon JJ et al (2017) Invader Relative Impact Potential: a new metric to understand and predict the ecological impacts of existing, emerging and future invasive alien species. J Appl Ecol 54:1259-1267. https://doi.org/10.1111/1365-2664.12849

Doherty, T. S., Glen, A. S., Nimmo, D. G., Ritchie, E. G., \& Dickman, C. R. (2016). Invasive predators and global biodiversity loss. Proceedings of the National Academy of Sciences, 113(40), 11261-11265

Early R, Bradley BA, Dukes JS et al (2016) Global threats from invasive alien species in the twenty-first century and national response capacities. Nat Commun 7:12485. https://doi.org/10.1038/ncomms 12485

Ehrenfeld JG (2010) Ecosystem consequences of biological invasions. Annu Rev Ecol Evol Syst 41:59-80

Ellstrand NC, Schierenbeck KA (2000) Hybridization as a stimulus for the evolution of invasiveness in plants? Proc Natl Acad Sci USA 97:7043-7050

Epanchin-Niell RS (2017) Economics of invasive species policy and management. Biol Invasion 19:3333-3354. https://doi.org/10.1007/s10530-017-1406-4

Essl F, Dullinger S, Rabitsch W et al (2011) Socioeconomic legacy yields an invasion debt. Proc Natl Acad Sci 108:203-207. https://doi.org/10.1073/pnas.1011728108

European Environmental Agency (2012) Protected areas in Europe: an overview. EEA Report $N^{\circ}$ 5/2012. EU, Luxembourg

Faulkner KT, Robertson MP, Wilson JRU (2020) Stronger regional biosecurity is essential to prevent hundreds of harmful biological invasions. Glob Chang Biol 26:24492462. https://doi.org/10.1111/gcb.15006

Foxcroft L, Freitag-Ronaldson S (2007) Seven decades of institutional learning: managing alien plant invasions in the Kruger National Park, South Africa. Oryx 41:160-167. https://doi.org/10.1017/S0030605307001871

Foxcroft LC, Jarošík V, Pyšek P et al (2011) Protected-area boundaries as filters of plant invasions. Conserv Biol 25:400-405

Foxcroft LC, Pyšek P, Richardson DM et al (2017a) Plant invasion science in protected areas: progress and priorities. Biol Invasion 19:1353-1378. https://doi.org/10.1007/ s10530-016-1367-z

Foxcroft LC, Van Wilgen NJ, Baard JA, Cole NS (2017b) Biological invasions in South African National Parks. Bothalia 47:a2158. https://doi.org/10.4102/abc.v47i2. 2158 
Foxcroft LC, Pyšek P, Richardson DM, Genovesi P (2013) Plant invasions in protected areas: patterns, problems and challenges

Gaertner M, Biggs R, Te Beest M et al (2014) Invasive plants as drivers of regime shifts: identifying high-priority invaders that alter feedback relationships. Divers Distrib 20:733-744. https://doi.org/10.1111/ddi.12182

Gallardo B, Aldridge DC (2013) Priority setting for invasive species management: risk assessment of PontoCaspian invasive species into Great Britain. Ecol Appl 23:352-364

Gallardo B, Aldridge DC, González-Moreno P et al (2017) Protected areas offer refuge from invasive species spreading under climate change. Glob Chang Biol 23:5331-5343. https://doi.org/10.1111/gcb.13798

Gantchoff MG, Wilton CM, Belant JL (2018) Factors influencing exotic species richness in Argentina's national parks. PeerJ 6:e5514. https://doi.org/10.7717/peerj.5514

Gardener MR, Trueman M, Buddenhagen C et al (2013) A pragmatic approach to the management of plant invasions in galapagos BT: plant invasions in protected areas: patterns, problems and challenges. In: Foxcroft LC, Pyšek $\mathrm{P}$, Richardson DM, Genovesi P (eds) Plant Invasions in protected areas. Springer, Dordrecht, pp 349-374

Gardener MR, Atkinson R, Rentería JL (2010) Eradications and people: lessons from the plant eradication program in galapagos. Restor Ecol 18:20-29. https://doi.org/10. 1111/j.1526-100X.2009.00614.x

Geldmann J, Barnes M, Coad L et al (2013) Effectiveness of terrestrial protected areas in reducing habitat loss and population declines. Biol Conserv 161:230-238

Gill DA, Mascia MB, Ahmadia GN et al (2017) Capacity shortfalls hinder the performance of marine protected areas globally. Nature 543:665-669. https://doi.org/10. 1038/nature21708

Gioria M, Pyšek P, Moravcová L (2012) Soil seed bank in plant invasions: promoting species invasiveness and long-term impact on plant community dynamics. Preslia 84:327-350

Hartig F (2020) DHARMa: Residual diagnostics for hierarchical (multi-level/mixed) regression models. $\mathrm{R}$ package version 0.3.3.0

Haubrock PJ, Turbelin AJ, Cuthbert RN, et al (2021) Economic costs of invasive alien species across Europe. In: Zenni RD, McDermott S, García-Berthou E, et al (eds) The economic costs of biological invasions around the world. NeoBiota 67: 153-190. https://doi.org/10.3897/neobiota. 67.58196

Hejda M, Pyšek P, Jarosik V (2009) Impact of invasive plants on the species richness, diversity and composition of invaded communities. J Ecol 97:393-403

Heringer G, Almeida TE, Dittrich VAO et al (2020) Assessing the effectiveness of protected areas for the conservation of ferns and lycophytes in the Brazilian state of Minas Gerais. J Nat Conserv 53:125775. https://doi.org/10. 1016/j.jnc.2019.125775

Heringer G, Angulo E, Ballesteros-Mejia L, et al (2021) The economic costs of biological invasions in Central and South America: a first regional assessment. In: Zenni RD, McDermott S, García-Berthou E, et al (dds) The economic costs of biological invasions around the world.
NeoBiota 67: 401-426. https://doi.org/10.3897/neobiota. 67.59193

Hirsch H, Richardson DM, Le Roux JJ (2017) Introduction to the special issue: Tree invasions: towards a better understanding of their complex evolutionary dynamics. AoB Plants 9:plx014. https://doi.org/10.1093/aobpla/plx014

Hulme PE (2014) Invasive species challenge the global response to emerging diseases. Trends Parasitol 30:267-270

Hulme PE, Pyšek P, Pergl J et al (2014) Greater focus needed on alien plant impacts in protected areas. Conserv Lett 7:459-466. https://doi.org/10.1111/conl.12061

Hussner A, Stiers I, Verhofstad MJJM et al (2017) Management and control methods of invasive alien freshwater aquatic plants: a review. Aquat Bot 136:112-137. https:// doi.org/10.1016/j.aquabot.2016.08.002

Iacarella JC, Burke L, Davidson IC et al (2020) Unwanted networks: vessel traffic heightens the risk of invasions in marine protected areas. Biol Conserv 245:108553

James AN, Green MJB, Paine JR (1999) A global review of protected area budgets and staff. WCMC World Conservation Press, Cambridge

Kettunen M, Genovesi P, Gollasch S, et al (2009) Technical support to EU strategy on invasive alien species (IAS). Institute for European Environmental Policy (IEEP), Brussels, Belgium

Kourantidou M, Kaiser BA (2021) Allocation of research resources for commercially valuable invasions: Norway's red king crab fishery. Fish Res 237:105871. https://doi. org/10.1016/j.fishres.2020.105871

Latreille AC, Milesi P, Magalon H et al (2019) High genetic diversity but no geographical structure of Aedes albopictus populations in Réunion Island. Parasit Vectors 12:597. https://doi.org/10.1186/s13071-019-3840-x

Leroy B, Kramer AM, Vaissière A-C et al (2020) Analysing global economic costs of invasive alien species with the invacost $\mathrm{R}$ package. BioRxiv. https://doi.org/10.1101/ 2020.12.10.419432

Leung B, Lodge DM, Finnoff D et al (2002) An ounce of prevention or a pound of cure: bioeconomic risk analysis of invasive species. Proc R Soc London Ser B Biol Sci 269:2407-2413. https://doi.org/10.1098/rspb.2002.2179

Leverington F, Costa KL, Pavese H et al (2010) A global analysis of protected area management effectiveness. Environ Manage 46:685-698

Liebhold AM, Kean JM (2019) Eradication and containment of non-native forest insects: successes and failures. J Pest Sci 92:83-91. https://doi.org/10.1007/ s10340-018-1056-z

Lindsey PA, Miller JRB, Petracca LS et al (2018) More than \$1 billion needed annually to secure Africa's protected areas with lions. Proc Natl Acad Sci 115:E10788-E10796. https://doi.org/10.1073/pnas.1805048115

Liu X, Blackburn TM, Song T et al (2020) Animal invaders threaten protected areas worldwide. Nat Commun 11:2892. https://doi.org/10.1038/s41467-020-16719-2

Martins TLF, Brooke MDL, Hilton GM et al (2006) Costing eradications of alien mammals from islands. Anim Conserv 9:439-444

Mazza G, Tricarico E (eds) (2018) Invasive Species and Human Health, Vol. 10. CABI 
McCarthy DP, Donald PF, Scharlemann JPW et al (2012) Financial costs of meeting global biodiversity conservation targets: current spending and unmet needs. Science 338:946-949. https://doi.org/10.1126/science.1229803

Moodley D, Foxcroft LC, Novoa A et al (2020) Invasive alien species add to the uncertain future of protected areas. NeoBiota 57:1-5. https://doi.org/10.3897/neobiota.57. 52188

Nuñez MA, Pauchard A (2010) Biological invasions in developing and developed countries: does one model fit all? Biol Invasion 12:707-714. https://doi.org/10.1007/ s10530-009-9517-1

Paini DR, Sheppard AW, Cook DC et al (2016) Global threat to agriculture from invasive species. Proc Natl Acad Sci 113:7575-7579

Parker I, Simberloff D, Lonsdale W et al (1999) Impact: toward a framework for understanding the ecological effects of invaders. Biol Invasion 1:3-19. https://doi.org/10. 1023/A:1010034312781

Pejchar L, Mooney HA (2009) Invasive species, ecosystem services and human wellbeing. Trends Ecol Evol 24:497-504

Pimentel D, Zuniga R, Morrison D (2005) Update on the environmental and economic costs associated with alien-invasive species in the United States. Ecol Econ 52:273-288

Pysek P, Richardson DM, Pergl J et al (2008) Geographical and taxonomic biases in invasion ecology. Trends Ecol Evol 23:237-244. https://doi.org/10.1016/j.tree.2008.02.002

Pyšek P, Pergl J, Essl F et al (2017) Naturalized alien flora of the world: species diversity, taxonomic and phylogenetic patterns, geographic distribution and global hotspots of plant invasion. Preslia 89:203-274

Pyšek P, Hulme PE, Simberloff D et al (2020) Scientists' warning on invasive alien species. Biol Rev 95:1511-1534. https://doi.org/10.1111/brv.12627

Ricciardi A, Iacarella JC, Aldridge DC et al (2021) Four priority areas to advance invasion science in the face of rapid environmental change. Environ Rev. https://doi.org/10. 1139/er-2020-0088

Richardson DM, Rejmánek M (2011) Trees and shrubs as invasive alien species: a global review. Divers Distrib 17:788-809

Richardson DM, Abrahams B, Boshoff N et al (2020) South Africa's centre for invasion biology: an experiment in invasion science for society BT: biological invasions in South Africa. In: van Wilgen BW, Measey J, Richardson DM et al (eds) Biological invasions in South Africa, Invading N. Springer International Publishing, Cham, pp 879-914

Rico-Sánchez AE, Sundermann A, López-López E, TorresOlvera MJ, Mueller SA, Haubrock PJ (2020) Biological diversity in protected areas: Not yet known but already threatened. Global Ecol Conserv 22:e01006

Rico-Sánchez AE, Haubrock PJ, Cuthbert RN, et al (2021) Economic costs of invasive alien species in Mexico. In: Zenni RD, McDermott S, García-Berthou E, et al (eds) The economic costs of biological invasions around the world. NeoBiota 67: 459-483. https://doi.org/10.3897/ neobiota.67.63846

Robertson PA, Mill A, Novoa A et al (2020) A proposed unified framework to describe the management of biological invasions. Biol Invasion 22:2633-2645. https://doi.org/10.1007/s10530-020-02298-2

Rodrigues ASL, Gaston KJ (2001) How large do reserve networks need to be? Ecol Lett 4:602-609. https://doi.org/ 10.1046/j.1461-0248.2001.00275.x

Rodrigues ASL, Andelman SJ, Bakarr MI et al (2004) Effectiveness of the global protected area network in representing species diversity. Nature 428:640-643. https:// doi.org/10.1038/nature02422

Le Saout S, Hoffmann M, Shi Y et al (2013) Protected areas and effective biodiversity conservation. Science 342:803-805. https://doi.org/10.1126/science.1239268

Schaffner F, Medlock JM, Van Bortel W (2013) Public health significance of invasive mosquitoes in Europe. Clin Microbiol Infect 19:685-692. https://doi.org/10.1111/ 1469-0691.12189

Schaffner U, Steinbach S, Sun Y et al (2020) Biological weed control to relieve millions from Ambrosia allergies in Europe. Nat Commun 11:1745. https://doi.org/10.1038/ s41467-020-15586-1

Seebens H, Blackburn TM, Dyer EE et al (2017) No saturation in the accumulation of alien species worldwide. Nat Commun 8:1-9. https://doi.org/10.1038/ncomm s14435

Seebens H, Bacher S, Blackburn TM et al (2020) Projecting the continental accumulation of alien species through to 2050. Glob Chang Biol 27:970-982. https://doi.org/10. 1111/gcb.15333

Shackleton RT, Bertzky B, Wood LE et al (2020a) Biological invasions in World Heritage Sites: current status and a proposed monitoring and reporting framework. Biodivers Conserv 29:3327-3347. https://doi.org/10.1007/ s10531-020-02026-1

Shackleton RT, Foxcroft LC, Pyšek P et al (2020b) Assessing biological invasions in protected areas after 30 years: revisiting nature reserves targeted by the 1980s SCOPE programme. Biol Conserv 243:108424. https://doi.org/ 10.1016/j.biocon.2020.108424

Strydom M, Veldtman R, Ngwenya MZ, Esler KJ (2017) Invasive Australian Acacia seed banks: size and relationship with stem diameter in the presence of gall-forming biological control agents. PLoS ONE 12:e0181763. https:// doi.org/10.1371/journal.pone.0181763

Trueman M, Atkinson R, Guézou A, Wurm P (2010) Residence time and human-mediated propagule pressure at work in the alien flora of Galapagos. Biol Invasion 12:3949I3960

UNEP-WCMC and IUCN (2020) Protected planet: the world database on protected areas (WDPA) [Online] Cambridge, UK: UNEP-WCMC and IUCN. www.protectedp lanet.net

van Wilgen BW, Measey J, Richardson DM et al (2020) Biological invasions in South Africa: an overview. In: van Wilgen BW, Measey J, Richardson DM et al (eds) Biological invasions in South Africa, invading N. Springer International Publishing, Cham, pp 3-31

Vilà M, Weber E, D'Antonio CM (2000) Conservation implications of invasion by plant hybridization. Biol Invasion 2:207-217

Vitousek PM (1990) Biological invasions and ecosystem processes: towards an integration of population biology and ecosystem studies. Oikos 57:7-13 
Warren RJ II, King JR, Tarsa C et al (2017) A systematic review of context bias in invasion biology. PLoS ONE 12:e0182502

Wickham H (2016) ggplot2: Elegant graphics for data analysis

van Wilgen BW, Khan A, Marais C (2010) Changing perspectives on managing biological invasions: insights from South Africa and the working for water programme. Fifty Years Invasion Ecol, pp 377-393

Wilkie DS, Carpenter JF, Zhang Q (2001) The under-financing of protected areas in the Congo Basin: so many parks and so little willingness to pay. Biodivers Conserv 10:691-709

Zenni RD, Nuñez MA (2013) The elephant in the room: the role of failed invasions in understanding invasion biology. Oikos 122:801-815. https://doi.org/10.1111/j. 1600-0706.2012.00254.x

Ziller SR, Dechoum MS, Silveira RAD et al (2020) A priority-setting scheme for the management of invasive nonnative species in protected areas. NeoBiota 62:591-606. https://doi.org/10.3897/neobiota.62.52633

Publisher's Note Springer Nature remains neutral with regard to jurisdictional claims in published maps and institutional affiliations. 